\title{
Biomarker und Histologie bei idiopathischen inflammatorischen Myopathien
}

\section{Biomarkers and Histology in Idiopathic Inflammatory Myopathies}

Autoren

Udo Schneider ${ }^{1}$, Werner Stenzel ${ }^{2}$, Bruno Stuhlmüller ${ }^{1}$

Institute

1 Medizinische Klinik mit Schwerpunkt für Rheumatologie und Klinische Immunologie, Charité Universitatsmedizin Berlin, Berlin, Deutschland

2 Institut für Neuropathologie, Charité Universitätsmedizin Berlin, Berlin, Deutschland

Schlüsselwörter

Biomarker, Histologie, idiopathisch, inflammatorisch,

Myopathie

Key words

biomarker, histology, idiopathic, inflammatory, myopathy

Bibliografie

Akt Rheumatol 2021; 46: 343-360

DOI 10.1055/a-1548-8934

ISSN 0341-051X

(C) 2021. Thieme. All rights reserved.

Georg Thieme Verlag, Rüdigerstraße 14,

70469 Stuttgart, Germany

Korrespondenzadresse

Udo Schneider

Rheumatologie

Charité Universitätsmedizin Berlin

Charitéplatz1

10117 Berlin

Deutschland

Tel.: 004930450513318 , Fax: 0049304507513057

udo.schneider@charite.de

\section{ZUSAMMENFASSUNG}

Die idiopathischen inflammatorischen Myopathien (IIM) sind eine Gruppe entzündlicher Muskelerkrankungen für deren Diagnosestellung, Verlaufsbeurteilung, Prognoseabschätzung und Risikostratifizierung Biomarker eine jeweils essentielle Rolle spielen. Biomarker in diesem Kontext können sowohl „herkömmliche“ serologische Marker wie Muskelenzyme oder Autoantikörper, histologische Marker wie entitätsspezifische inflammatorische Muster, aber auch genomische und genetische Marker sein. Der vorliegende Artikel gibt einen Überblick über bewährte und innovative Marker.

\section{ABSTRACT}

Idiopathic inflammatory myopathies (IIM) are a group of inflammatory muscle diseases in which biomarkers play an essential role in diagnosing the disease, evaluating its course and prognosis and stratifying each patient for disease-specific risks. In this context, biomarkers may be conventional serologic markers such as muscle enzymes or autoantibodies, specific inflammatory patterns in histology or genomic/genetic markers. 


\begin{tabular}{|c|c|}
\hline \multicolumn{2}{|c|}{ ABKÜRZUNGEN } \\
\hline A & Adult \\
\hline AK & Antikörper \\
\hline ASA & anti-Synthetase spezifische Antikörper \\
\hline ASS & anti-Synthetase Syndrom \\
\hline CEIA & Chemilumineszenz Enzym Immunoassay \\
\hline Cy & Zytoplasma \\
\hline DNA & Desoxy-Ribonukleinsäure \\
\hline DM & Dermatomyositis \\
\hline EGF & Epidermaler Wachstumsfaktor \\
\hline EGR-1 & Epidermaler Wachstumsfaktor Rezeptor 1 \\
\hline ERM & Endosplasmatisches Retikulum \\
\hline Exp. & experimentell \\
\hline Fkt. & Funktion \\
\hline IF & Immun Fluoreszenz \\
\hline IFN & Interferon \\
\hline (s)IBM & (sporadische) Einschlußkörperchen Myositis \\
\hline IIM & Idiopathische inflammatorische Myositis \\
\hline ITA & Immunoturbidimeteric Assay \\
\hline $\mathrm{J} / \mathbf{j}$ & Juvenil/juvenil \\
\hline kDa & Kilodalton \\
\hline MCTD & Mischkollagenose \\
\hline mRNA & Protein kodierende messenger RNA \\
\hline mi & Mitochondrium \\
\hline miRNA & mikro RNA \\
\hline NM-IIM & nekrotisierende Myopathische IIM \\
\hline $\mathrm{Nu}$ & Nukleus bzw. Zellkern \\
\hline PM & Polymyositis \\
\hline pSS & Sjoegren Syndrom \\
\hline RA & Rheumatoide arthritis \\
\hline RNA & Ribonukleinsäure \\
\hline SSc & Sklerodermie \\
\hline SLE & Systemischer Lupus Erythematosus \\
\hline tRNA & Transfer RNA \\
\hline qPCR & quantitative Polymerase Kettenreaktion \\
\hline u.a. & und anderem \\
\hline unbek. & unbekannt \\
\hline WB & Western Blot \\
\hline ZM & Zellmembran \\
\hline
\end{tabular}

\section{Einleitung}

Die Idiopathischen inflammatorischen Myopathien (IIM) sind eine Gruppe heterogener entzündlicher und chronischer Erkrankungen, zu deren Klassifikation es in den vergangenen Jahren mehrere neue unterschiedliche Vorschläge gab, so dass hier derzeit noch kein einheitlicher Konsens besteht. In diesem Beitrag wollen wir deshalb einen Überblick über klinisch und histopathologisch relevante Biomarker geben und auch die Neuerungen auf molekularer Ebene beleuchten.

Anlass für Alternativvorschläge zu konventionellen Klassifikationskriterien war einerseits die Identifizierung neuer Subgruppen wie z. B. die immunmediierten nekrotisierenden Myopathien (IMNM) oder die Myositis im Kontext des Antisynthetase-Syndroms
(ASS), andererseits aber auch das zunehmende Wissen um Autoantikörper als prognostisch oder differentialtherapeutisch bedeutsame Biomarker. Konventionelle laborchemische Parameter wie die Creatinkinase (CK) Werte haben einen gut bekannten Wert in der täglichen Routine, der für die verschiedenen Myositiden jedoch differenziert betrachtet werden sollte. [1-6].

Wir möchten auch auf, potentielle Biomarker eingehen, die ihre Wertigkeit in der Routine noch konsolidieren müssen.

Myopathologische Untersuchungen der erkrankten Skelettmuskulatur lassen in vielen Fällen eine Einordnung mit hoher Genauigkeit zu, sodass eine Muskelbiopsie für die präzise Zuordnung in den meisten Fällen nicht nur hilfreich, sondern auch notwendig ist [5, 7-9].

Es wird hier eine detaillierte Beschreibung morphologischer Charakteristika der verschiedenen Krankheitsformen der IIMs gegeben, sowie auf Korrelationen mit Biomarkern hingewiesen, die dann gesamthaft als Mosaik für die Versorgung von Myositis-Patienten nutzbar sind (z. B. TIF1Y + DM, gering erhöhte CK Werte, kapilläre Komplementablagerungen, Tumorassoziation).

\section{Konventionelle Biomarker}

\section{Muskelenzyme}

Das häufigste sowohl in der Erstdiagnostik als auch in der Verlaufsbeurteilung der IIM verwendete Muskelenzym ist die Creatininkinase (CK). Sie stellt immer noch den wichtigsten Routinemarker dar. Eine Erhöhung des CK-Wertes ist nicht spezifisch für die IIM, sondern kann durch eine Vielzahl anderer Einflüsse und Erkrankungen wie z. B. Thyreopathien, medikamentös-toxische Schäden, nichtentzündliche Muskelerkrankungen (wie z. B. Muskeldystrophien) Muskeltraumen oder auch (Ausdauer-)Sport, hervorgerufen werden. Aufgrund dieser auch möglichen belastungsabhängigen CK-Erhöhungen lohnt eine Verlaufskontrolle nach mehrtägiger körperlicher Schonung vor Einleitung weiterer Maßnahmen.

Der individuelle CK-Normwert ist von der Muskelmasse und somit auch von Alter, Geschlecht, Trainingszustand und der Ethnizität abhängig [10]. Zu betonen ist, dass die Höhe der CK auch bei etablierter Diagnose einer IIM nicht 1:1 mit Floridität der Erkrankung gleichzusetzen ist, sondern intraindividuell zu betrachten ist und deshalb auch bei deutlicher Erhöhung nicht zwingend mit einer ausgeprägten Muskelschwäche einhergehen muss. Vice versa kann trotz nur diskret erhöhter CK-Werte ein hochflorides, immobilisierendes Krankheitsbild vorliegen. Die Höhe der CK-Werte ist bei den verschiedenen IIM oft, charakteristisch v verändert. Außerdem lässt sich der CK-Wert bei einigen Erkrankungen sehr, bei anderen weniger gut als Verlaufsmarker nutzen. Andere Enzyme, wie z. B. Myoglobin aber auch LDH und Aldolase erbringen im Allgemeinen keinen zusätzlichen Informationswert. Die Transaminasen (ALT, AST) spielen in der Verlaufsbeurteilung juveniler Myositiden eine gewisse Rolle, sollten aber auch beim Erwachsenen unbedingt initial bestimmt werden, um einen Ausgangsbefund zu haben, um eine (oft vermeintliche) medikamentöse Hepatotoxizität z. B. unter Methotrexattherapie, die tatsächlich Ausdruck persisitierender Krankheitsaktivität ist, zuordnen zu können. 


\section{Systemische Entzündungsparameter}

Systemische Entzündungsparameter wie CRP und die Blutsenkungsgeschwindigkeit (BSG) sind bei den IIM nicht zwingend oder nur diskret erhöht. Bei Verlaufsformen mit schwerer interstitieller Lungenbeteiligung besteht eine Assoziation zu erhöhten Entzündungsparametern [11].

\section{Troponine}

Troponine gelten als myokardspezifisch und spielen deshalb eher im Rahmen der kardialen Diagnostik, insbesondere im Bereich des akuten Koronarysyndroms eine wesentliche Rolle [12]. Im Kontext der IIM werden Troponine oft zum Nachweis bzw. zur Verlaufsbeurteilung einer kardialen Affektion herangezogen [13]. Eine deutliche Erhöhung herzmuskelspezifischer Enzyme ist allerdings keinesfalls mit dem Beweis einer kardialen Manifestation einer Myositis gleichzusetzen, da insbesondere Troponin-T bei Muskelerkrankungen erhöht ist [14].

\section{Krebs von den Lungen- assoziiertes Antigen 6 (KL-6)}

KL-6 ist ein vor allem im asiatischen Raum gebräuchlicher Biomarker für interstitielle Lungenerkrankungen (ILD), der auch im Kontext IIM-assoziierter-ILD untersucht wurde, aber noch nicht breit verfügbar ist und dessen Wertigkeit im Kontext der IIM noch nicht abschließend beurteilt werden kann [15].

\section{Myositisspezifische und Myositisassoziierte Antikörper (MSA/MAA)}

Die Beschreibung neuer entitätsspezifischer Antikörper hat die Diagnostik der IIM in den vergangenen Jahren entscheidend vorangebracht, aber auch die eingangs geschilderten Diskussionen über sinnvolle Klassifikationen mitentfacht. Generell unterscheidet man myositisspezifische Antikörper (MSA), deren signifikanter Nachweis mit einer spezifischen Krankheitsentität assoziiert ist von myositisassoziierten Antikörpern (MAA), deren Nachweis „vieldeutiger“ ist und die begleitend zu einem MSA (häufig: Ro52-AK) oder isoliert (häufig: Ku-AK) auftreten können. Etwa 60\% der Patienten mit IIM weisen einen positiven AK (MSA oder MAA) auf [16]. Bei der DM sind die folgenden MSA gängig: TIF1-gamma, NXP2-, Mi2-, MDA5und SAE-; beim ASS: Jo1-, PL7-, PL12-, OJ-, EJ-, KS-, Ha-, Zo-; bei der IMNM SRP- und HMGCoR- und für die sporadische Einschlußkörpermyositis (sIBM) der c1NA -(Synonym Mup44) AK.

Auf die einzelnen MSA gehen wir weiter unten krankheitsspezifisch sowie in den $>$ Tab 1A-C ein. Methodisch werden MSA und MAA häufig mithilfe kommerziell erhältlicher Line-Blots detektiert, die sich in Art und Zahl der aufgetragenen Antigene, aber auch Sensitivität und Spezifität bgzl. des jeweiligen Antikörpernachweises unterscheiden.

In Analogie zur Stufendiagnostik der Kollagenosen wird in der Regel primär oder simultan eine indirekte Immunfluoreszenz (IIF) durchgeführt. Da viele MSA wie z. B. die häufigen ASS-Antikörper in der IIF eine oft rein zytoplasmatische Immunfluoreszenz hervorrufen, entsteht die Problematik eines vermeintlichen Erkrankungsauschlusses bei formal negativem Befund für antinukleäre Antikörper. Um diesem Trugschluss nicht zu unterliegen, lohnt sich der Kontakt mit dem befundenden Autoimmunlabor, um zu verstehen, wie ein rein zytoplasmatischer IIF-Befund berichtet wird.
Perspektivisch verbessert wird die IIF-Befundübermittlung durch die Einführung einer einheitlichen Klassifikation für die detektierten Fluoreszenzmuster („ICAP“, [17]). Typische zytoplasmatische Immunfluoreszenz Muster für IIM und insbesondere AntiSynthetase-Syndrome wären „zytoplasmatisch fein gesprenkelt“ (ICAP-Klassifikation „AC-19“, häufig bei PL-7 oder PL-12 AK) oder „zytoplasmatisch dicht fein gesprenkelt“ (AC-20, häufig bei Jo1AK)).

\section{Myositis-Blots}

Kommerziell erhältliche Blots dominieren mittlerweile die MSA/ MAA-Diagnostik. Je nach verwendetem Blot differiert Zahl und Zusammensetzung der aufgetragenen Antigene. Sensitivität und Spezifität hängen - wie bei jeder Untersuchung - entscheidend von der Prä-Test Wahrscheinlichkeit ab, sodass der große Vorteil eines schnellen und umfassenden diagnostischen Fortkommens bei unkritischer Anwendung durch unspezifische Positivbefunde und daraus ev. resultierende Interpretationsschwierigkeiten ein klein wenig getrübt wird. Unbedingt sinnvoll ist Kongruenz von Klinik, Immunfluoreszenz, Myositis-Blot und so verfügbar Histologie kritisch zu hinterfragen und bei diskordanter Konstellation den isolierten Nachweis eines MSAs - gerade auch bei grenzwertigen Befunden- nicht mit einer gesicherten Diagnose gleichzusetzen oder allein hierauf basierend ein Therapiekonzept zu begründen (zur weiteren Prädiagnostik vor Biopsie s.a. Infobox/— Tab. 2).

\section{Genomische Untersuchungen}

Patienten mit DM weisen eine verstärkte Expression von IFN Typ-I induzierten Genen sowohl im Muskelgewebe als auch in der Haut und im Serum auf. Im Vergleich zu Patienten mit ASS, IMNM und IBM fällt die Expression dieser Gene different zwischen ASS und IBM, im Vergleich hierzu bei der IMNM eher moderat bis niedrig aus $[18,19]$. Die Expression von IFN-gamma (Typ-II) ist bei der IBM und beim ASS hochreguliert. Insgesamt korreliert die Expression von IFN-induzierbaren Genen mit der Expression weiterer Gene, die mit Entzündung, Muskelatrophie und Muskelregeneration assoziiert sind [19]. Da insbesondere für die DM eine eindeutige Typ-I IFN abhängige Pathogenese bewiesen ist, wäre es wünschenswert, einen oder mehrere dieser molekularen Biomarkern ( $>$ Tab. 1D-F), die zuverlässig diese ,Gensignatur` im Patientenserum abbilden, für die Diagnostik und auch die Therapieüberwachung einzusetzen.

Neben den oben genannten genetischen Befunden zeigten genomische Untersuchungen eine sehr gute Korrelation zwischen einer erhöhten Expression von Genen, die eine IFN Typ-I Signatur zeigen ,einer differentiellen Expression der mikro-RNA ,miR146a und weiteren molekularen Kandidatengenen [20]. Die miR146a, wurde auch bereits schon zuvor bei Patienten mit SLE beschrieben. Diese miRNA ist in der Lage, den IFN Typ-1-Signalweg negativ zu regulieren [21]. In der genannten Studie wurden neben miR-146a auch noch 69 weitere Mikro-RNAs untersucht, von denen einige hoch-, andere herunterreguliert sind. Die Autoren schließen mit der Bemerkung, das eine genaue Entschlüsselung zur funktionellen Rolle und den Steuerungswegen zu mikro-RNAs wünschenswert wäre. Somit bleibt abzuwarten inwieweit sich hier ein für die Praxis relevanter Biomarker abzeichnet. 


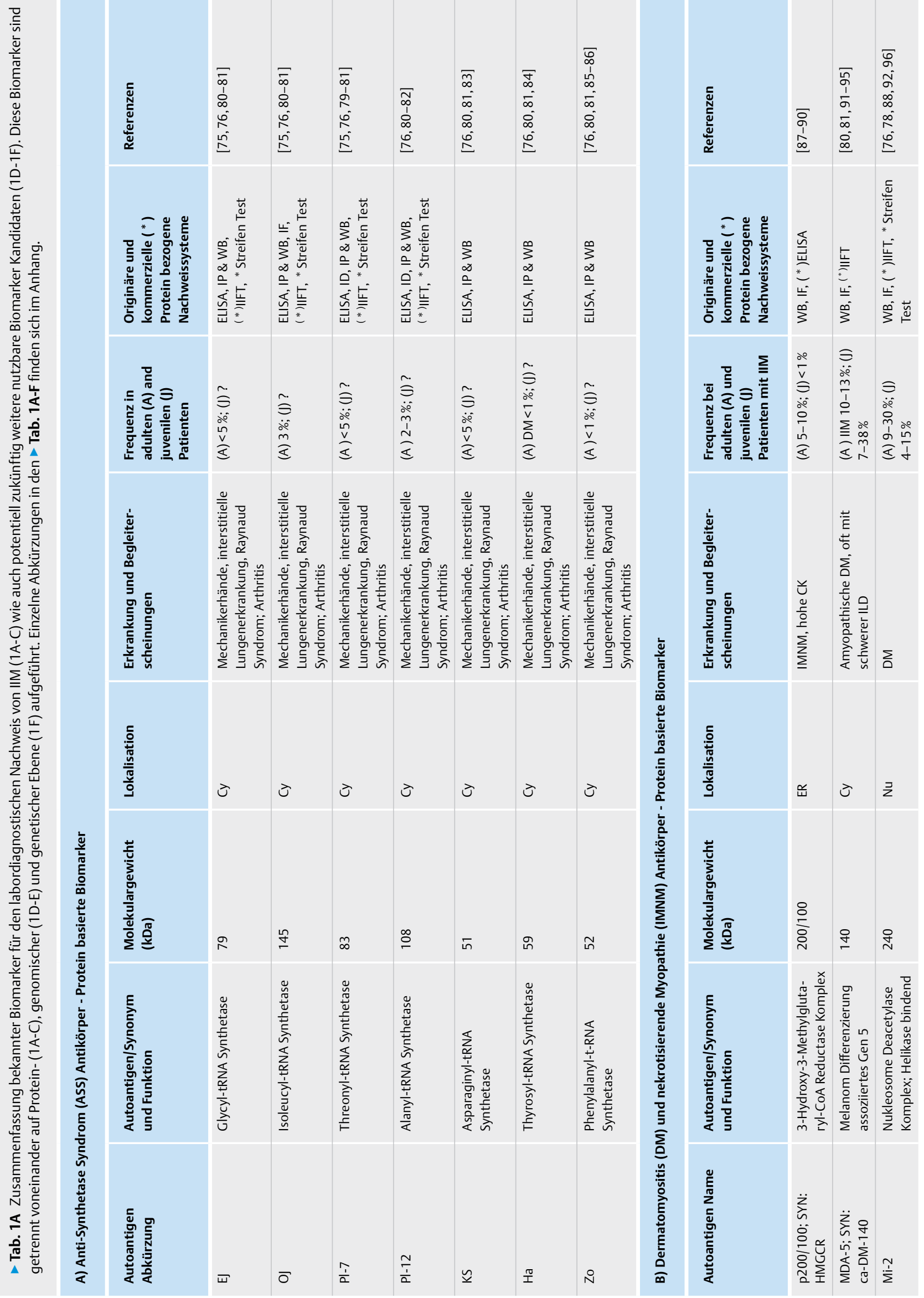




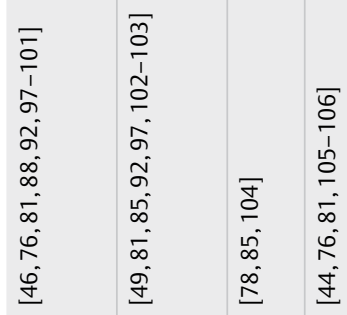

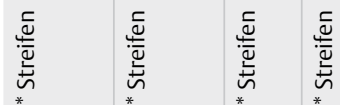

占占占占

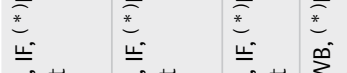

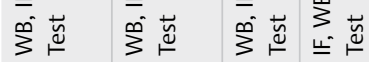

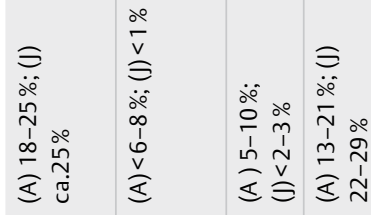

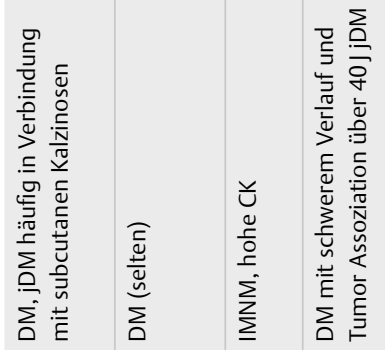

$\bar{z}$ ₹ $\stackrel{x}{\bar{y}}$

$\frac{\sqrt{2}}{2} \frac{\sqrt{2}}{\frac{2}{5}}$

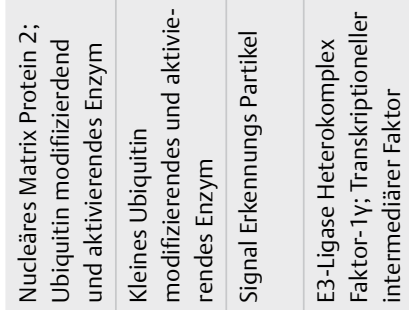

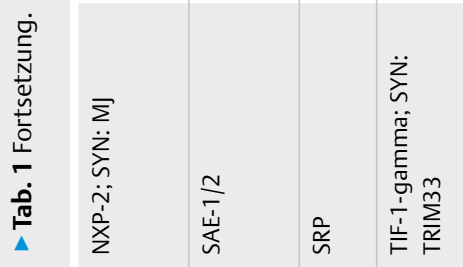

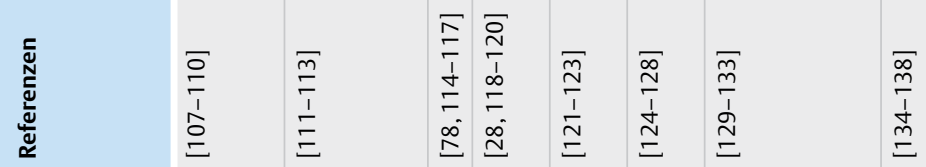

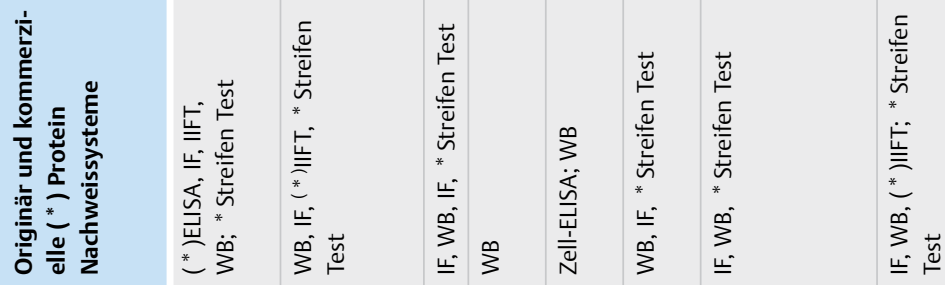

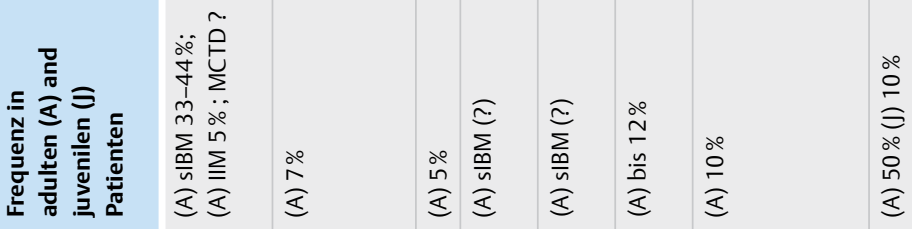

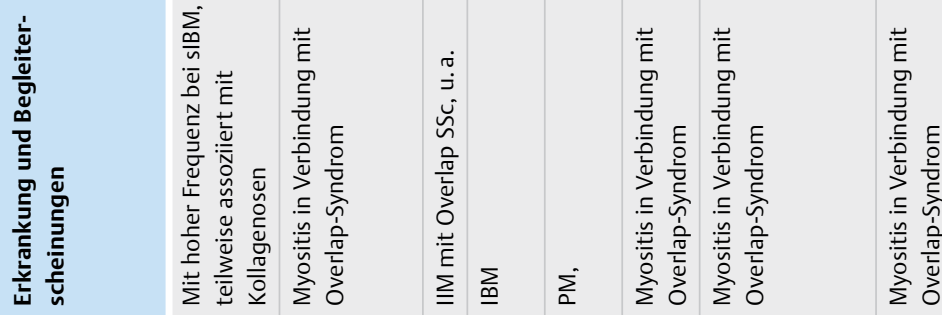

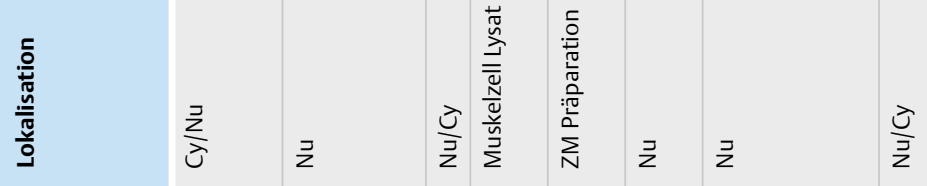

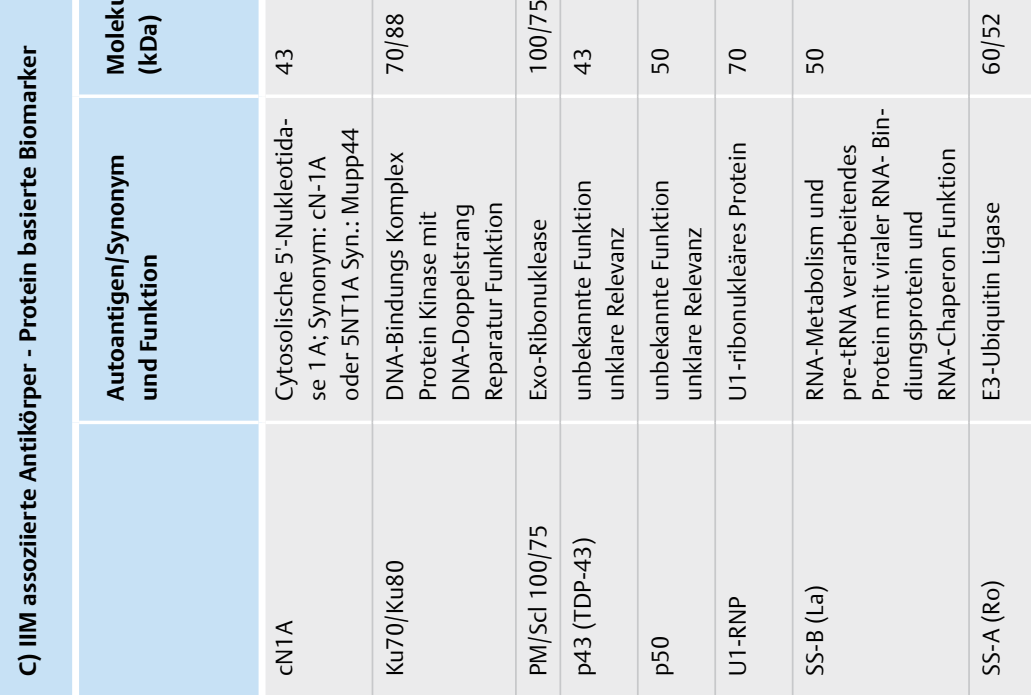




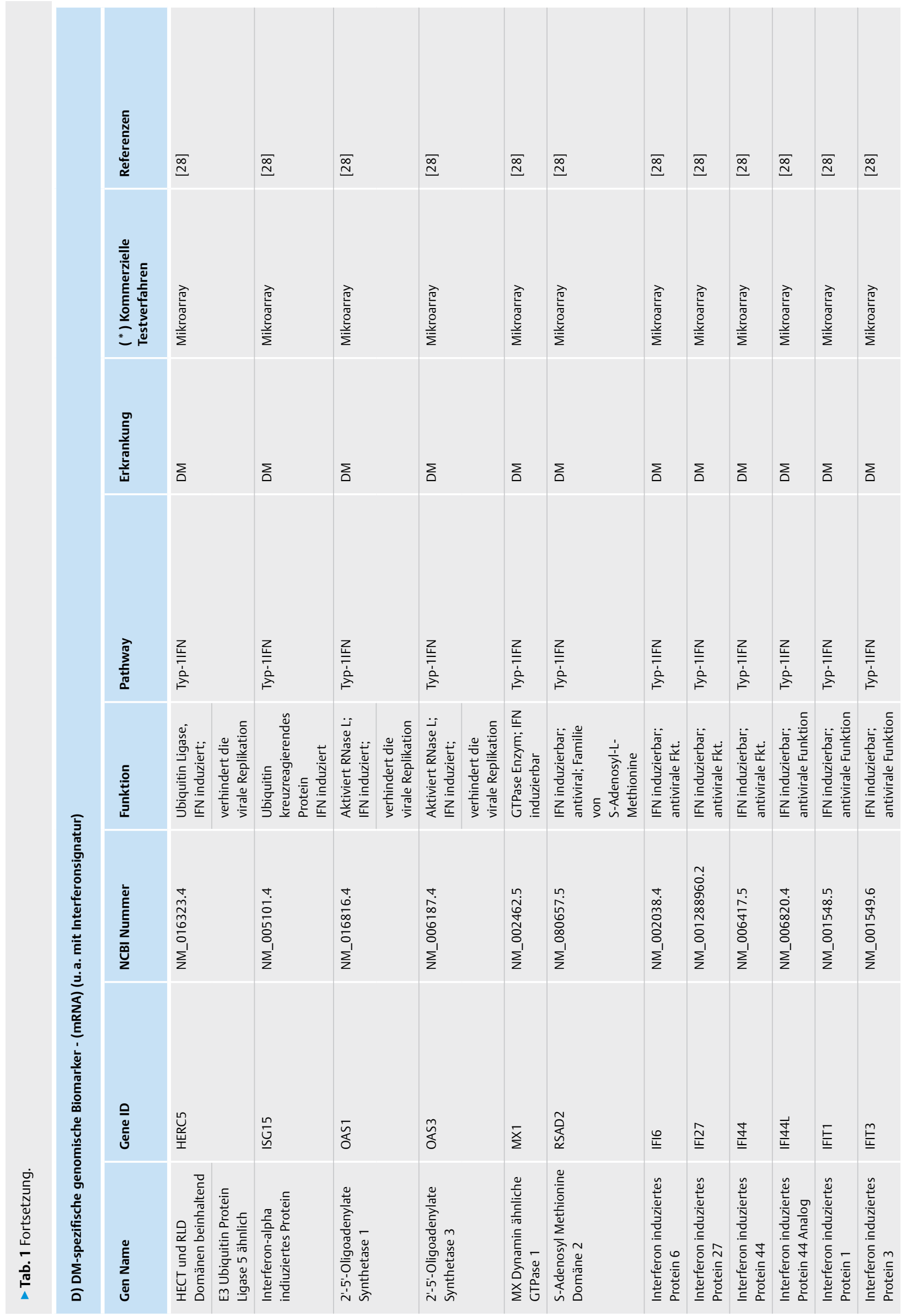



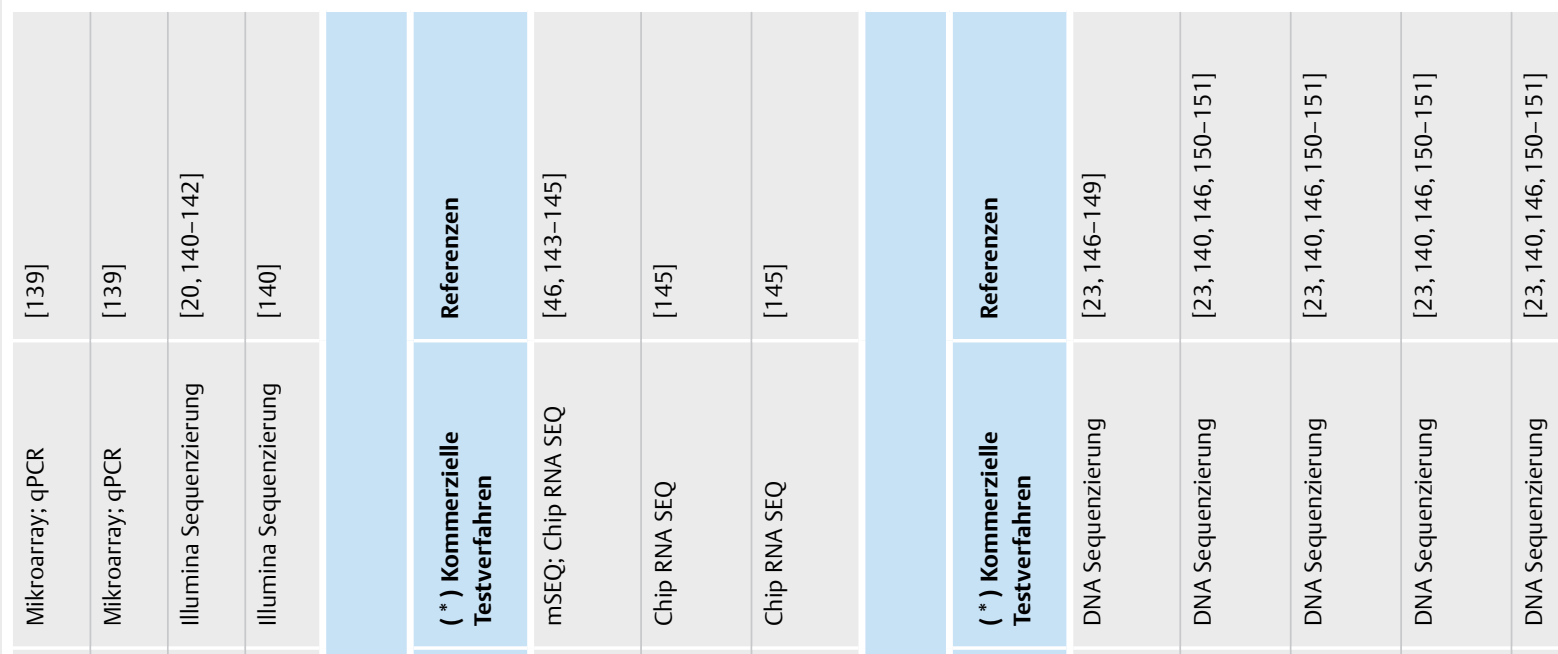

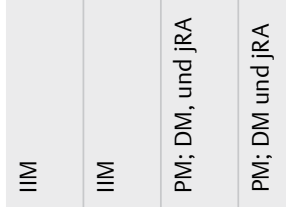
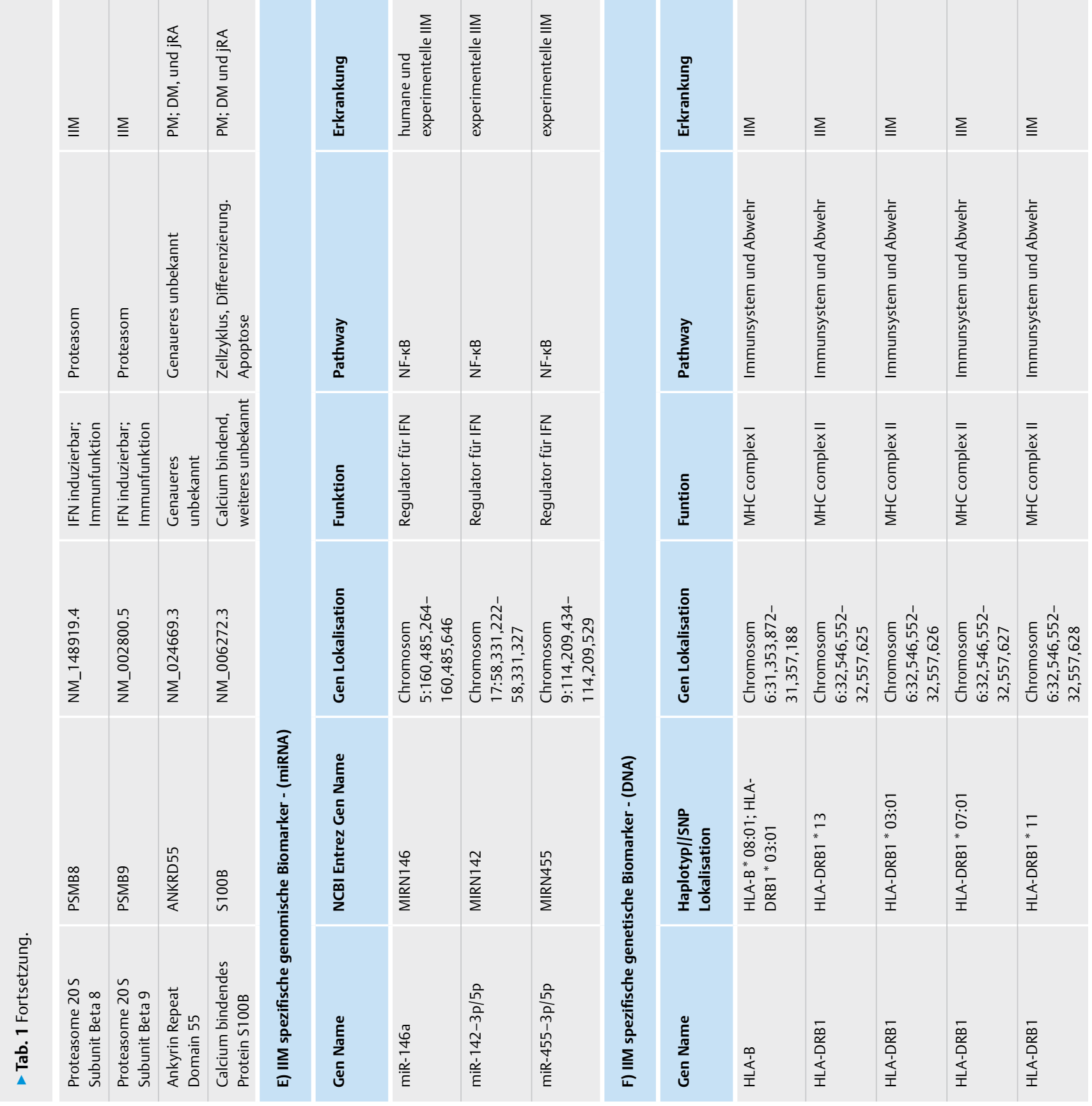


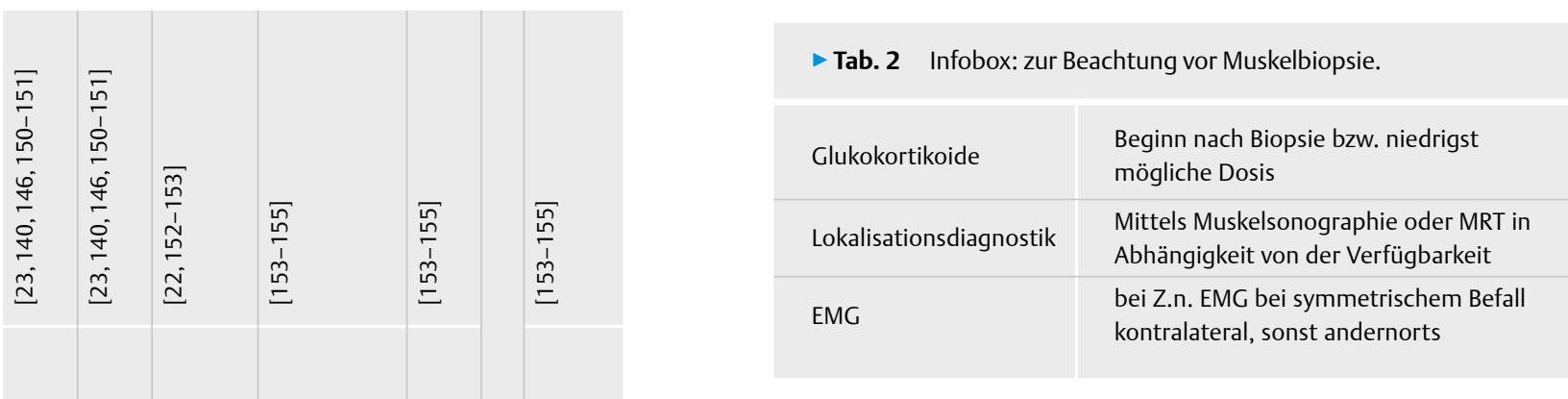

\section{Genetische Untersuchungen mit HLA-Haplotypen}

Interessanterweise zeigen sich bei Erkrankten mit IIM genetische Assoziationen mit HLA-Klasse-I und überwiegend mit HLA-KlasseII Haplotypen ( $\triangleright$ Tab. 1F). Dies gilt für IIM mit Autoantikörpern gegen i) anti-Jo- 1 (HLA-B ${ }^{*} 08: 01, p=2,28 \times 10-53$ und HLADRB1 * 03:01, $p=3,25 \times 10-9)$, ii)anti-PM/SCl (HLA-DQB1 * 02:01, $\mathrm{p}=1,47 \times 10-26)$ und iii)anti-CN1A (HLA-DRB1 ${ }^{*} 03: 01$, $p=1,40 \times 10-11)$. Außerdem wurden mit diesem Haplotyp iv) unabhängige Assoziationen mit anti-Mi-2 (HLA-DRB $1{ }^{*}$ 07:01, $\mathrm{p}=4,92 \times 10-13), \mathbf{v})$ anti-HMGCoR-Autoantikörpern (HLA$\mathrm{DRB1} * 11, \mathrm{p}=5,09 \times 10-6)$, wie auch genetische Assoziationen vi) des HLA-DQB1 Haplotyps mit anti-TIF1Y-Autoantikörpern identifiziert die sich möglicherweise zwischen erwachsenen und jugendlichen Patienten mit IIM unterscheiden [22, 23]. Keine signifikanten genetischen Assoziationen zeigten sich bei IIM Patienten die NXP2-, MDA5- oder SAE-Antikörper positiv waren [23]. Diese Assoziationen sind aus genetischer Sicht interessant, helfen jedoch in der täglichen Routine nicht bei der diagnostischen oder prognostischen Zuordnung. Genomische Erkenntnisse könnten zukünftig tiefere Einblicke in die Pathogenese einzelner IIM ermöglichen.

\section{Dermatomyositis (DM)}

Das klassische histomorphologische Bild einer DM wurde erst zu Beginn der 90-er Jahre von Dalakas und anderen genauer beschrieben und danach über Konsensuskriterien im Jahr 2003 klinikopathologisch genauer gefasst [24]. Vorliegen dabei muss eine i) subakute symmetrische Gliedergürtelschwäche, ii) DM-typische Hauterscheinungen und iii) eine perifaszikuläre Muskelfaseratrophie. Durch die Identifikation DM- spezifischer Autoantikörper lassen sich jedoch unterschiedliche klinische Bilder zuordnen, die auch morphologisch voneinander abgrenzbar sind [5, 7, 9]. Somit lassen sich diese beschriebenen Autoantikörper als Biomarker nutzen, um nicht nur grob eine DM zu diagnostizieren, sondern auch einen bestimmten Subtyp innerhalb der Dermatomyositiden festzustellen. Zudem lässt sich bei der DM als, einender' Pathomechanismus eine IFN Typ-I Signatur, sowohl lokal im erkrankten Muskel [25-27] als auch systemisch im Blut nachweisen [28]. Erhöhte Typ-I IFN Werte können jedoch auch bei anderen Erkrankungen auftreten [29] . Somit könnten IFN Typ-I oder eine Kombination von Genen als charakteristische transkriptionelle Signatur genutzt werden [18, 19, 25-27, 30-33]. Auf histomorphologischer Ebene können diese Typ-I IFN-Signatur-abhängigen Moleküle (MxA, ISG15, u. a.) ebenfalls konsistent dargestellt [26, 34-37] und somit als ,in situ" Biomarker genutzt werden [38]. 


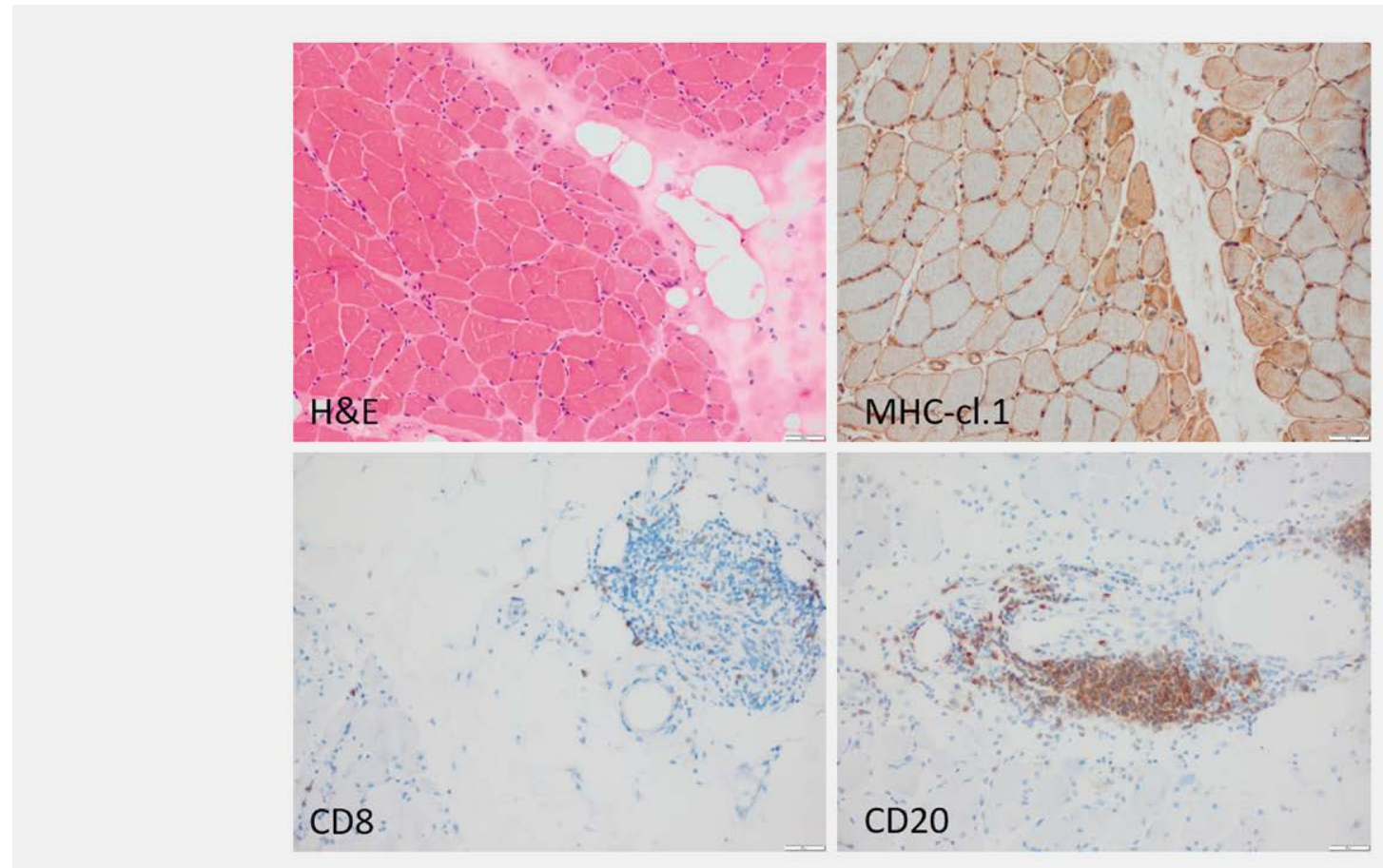

Abb. 1 Histologie bei DM.

Ultrastrukturell lassen sich in den Endothelzellen der endomysialen Kapillaren bei allen Dermatomyositiden sogenannte undulierende Tubuli nachweisen [25]. Dies ist ein ganz typischer Befund, der die Diagnose einer Dermatomyositis unterstreicht und somit ebenfalls als Gewebsbiomarker genutzt werden kann. Positive Erfahrungen bestehen lokal an der Charité für „Siglec1 “, einen globalen Interferon-I-Marker, der durchflußzytometrisch auf Monozyten gemessen wird und in der Erstdiagnostik sowie Verlaufsbeurteilung des systemischen Lupus bereits einen festen Stellenwert hat [38].

Auch bei den IIMs, insbesondere bei der DM könnte Siglec1 als Serum-Biomarker eingesetzt werden. Siglec1 ist in einer umschriebenen unizentrischen Kohorte signifikant erhöht und korreliert mit der Krankheitsaktivität (Graf et al., zur Publikation eingereicht).

\section{Anti-Mi-2 Autoantikörper-assoziierte DM}

Das klinische Bild einer Mi2-AK-positiven DM ist das einer „klassischen“ DM mit ausgeprägten und typischen Hautveränderungen (Gottron'sche Papeln, heliotropes Erythem im Dekolleté und Nackenbereich sowie auf den Wangen) und relativ ausgeprägter proximal betonter Muskelschwäche sowie deutlich erhöhten CK-Werten. Die Erkrankung manifestiert sich meist akut bis subakut. Eine Tumorassoziation ist für erwachsene Patienten selten beschrieben $[39,40]$.

\section{Morphologie}

Das morphologische Erscheinungsbild der anti-Mi-2-assoziierten DM ist charakteristisch. In allen Fällen findet man eine perifasziku- lär betonte Atrophie der Muskelfasern und dichte entzündliche Infiltrate, die sich vor allem im Perimysium und perivaskulär darstellen lassen. Es sind sowohl T-Lymphozyten als auch oft fokal clusternd B-Lymphozyten erkennbar.

Regelhaft erkennt man Komplementablagerungen, wie z. B. C5b-9 auf dem Sarkolemm und insbesondere auf den perifaszikulär gelegenen Fasern ( plementfärbung aufweisen, obwohl ein gering ausgeprägter Verlust von Kapillaren vorhanden ist. Es können Muskelfasernekrosen und Myophagozytosen auftreten. Das perifaszikuläre Muster wird beim Nachweis von MHC Klasse-I Antigenen deutlich weniger prominent; bei der Anfärbung der MHC Klasse II-Antigene- und/oder dem zusätzlichen Nachweis des neuralen Zell-Adhäsionsmoleküls (NCAM) oder des neonatalen Myosins und Utrophins ergeben sich spezifische Anfärbungen von regenerierenden Muskelfasern [41].

\section{Anti-TIF-1Y Autoantikörper-assoziierte DM}

Trotz schwerem Krankheitsbild mit ausgeprägter Muskelschwäche und den klassischen Hautveränderungen einer DM ist der CK-Wert bei Transcription intermediary factor 1-gamma (TIF1 $\boldsymbol{\gamma}$; > Tab. 1B) positiver DM oft nur leicht bis mäßig erhöht. Entsprechend lässt sich die CK nur begrenzt für ein Monitoring verwenden. Als klinische Besonderheit können Erythrodermien, ausgeprägte, therapierefraktäre Rötungen der gesamten Haut auftreten [42]. In der Immunfluoreszenz findet sich ein nukleäres Muster. Eine MalignomAssoziation im Sinne einer „cancer associated myositis“ (CAM) ist bei diesem Erkrankungsbild im Alter $>40$ ]. besonders häufig [43]. 


\section{Morphologie}

Typischerweise findet man bei der anti-TIF-1Y-Autoantikörperassoziierten DM ein schweres Ödem, welches das Perimysium betrifft und dieses deutlich verbreitert, jedoch nicht fragmentiert. Die Atrophie der perifaszikulären Muskelfasern ist sehr ausgeprägt und von allen Dermatomyositiden am auffälligsten. Das perifaszikuläre Muster kann auch mittels Färbungen mit Antikörpern gegen CD56 hervorgehoben werden. Die MHC Klasse I-Färbung ist sehr kräftig und betrifft oft auch zentrofaszikuläre Bereiche, während MHC Klasse II-Moleküle nicht sarkolemmal anfärbbar sind. Wichtigstes Merkmal sind ausgeprägte oft fokal betonte Komplementablagerungen auf Kapillaren, die bei erwachsenen Patienten mit der Präsenz von Malignomen positiv korrelieren. Sogenannte 'punched-out' Vakuolen (wie „ausgestanzt“ wirkende Vakuolen im Sarkoplasma im Gegensatz zu den beränderten „rimmed vacuoles“ bei IBM s.u.) finden sich oft in atrophen Fasern und korrelieren ebenfalls mit dem Auftreten von Malignomen [44]. Makrophagen finden sich diffus verteilt im Endo- und Perimysium ebenso wie diffus verteilte eher spärlich vorhandene Lymphozyten. B Zellen oder Plasmazellen sind selten.

\section{Anti-NXP-2 Autoantikörper-assoziierte DM}

Bei der juvenilen Dermatomyositis (jDM) tritt der gegen das antinukleäre Matrix Protein 2 (NXP2) gerichtete AK am häufigsten auf. Als Spezifikum geht dieses Erkrankungsbild oft mit ausgeprägten subkutanen Kalzifikationen einher, die auch im Erwachsenalter gelegentlich auftreten können. Im höheren Lebensalter besteht eine klare Tumorassoziation im Sinne einer CAM [45]. Der CK-Wert ist oft deutlich erhöht und in der Immunfluoreszenz zeigt sich ein nukleäres Muster.

\section{Morphologie}

Die morphologischen Veränderungen umfassen hier die typische perifaszikuläre Atrophie, klassische MHC Klasse I-Färbung mit perifaszikulär nach zentrofaszikulär abnehmendem Gradienten. MHC Klasse II-Moleküle finden sich sarkolemmal nicht. Es können teils flächig verteilte nekrotische Fasern oder Myophagozytosen bei sogenannten Mikroinfarkten vorkommen [46]. Lymphozyten sind etwas reichlicher als bei den anti-TIF1y Fällen im Perimysium betont und Komplementablagerungen können sarkolemmal auf Fasern zu finden, auf Kapillaren lässt sich Komplement manchmal ebenfalls darstellen [47].

\section{Anti-MDA5 Autoantikörper-assoziierte DM}

Melanoma differentiating Antigen 5 (MDA5; - Tab. 1B) AK-positive Erkrankungsbilder zeichnen sich oft durch einen a- oder hypomyopathischen Krankheitsverlauf aus, die CK ist entsprechend allenfalls diskret erhöht. Aufgrund der klinisch oft im Vordergrund stehenden rasch progredienten, vital bedrohlichen interstitiellen Lungenerkrankung in Verbindung mit typischen, wenn auch oft an den Phalangen eher beuge- als streckseitigen Hautveränderungen, wird auch der Begriff: ,Dermatopulmonales-Syndrom ' zur Beschreibung des Erkrankungsbildes verwendet.

MDA5-AK zeigen in der IIF ein zytoplasmatisches Muster. Ihre Titerhöhe, falls verfügbar, korreliert ebenso mit der Krankheitsaktivität wie das Ferritin im Serum [11].

\section{Morphologie}

Die Muskelbiopsien der anti-MDA-5 assoziierten DM zeigen ein nicht klassisch morphologisches Bild [48]). Hauptmerkmal ist eine sehr gering ausgeprägte entzündliche Infiltration des Muskels, die oft nur sehr fokal begrenzt im Perimysium und in Gefäßnähe erscheint.

Auch das typische Muster einer perifaszikulären Atrophie in verschiedenen Faszikeln ist nicht ausgeprägt. Hilfreich ist die MHC Klasse-I Färbung, die eine sarkolemmale Färbereaktion aufweist, wenngleich diese deutlich geringer ausgeprägt ist als bei anderen DM-Biopsien. Den ebenfalls klassischen Verlust von Kapillaren und undulierenden Tubuli in Endothelzellen, die sich per Elektronenmikroskopie nachweisen lassen, sieht man bei 'anti-MDA-5-DM Biopsien' nur in etwa $50 \%$ der Fälle [48]. T- und B-Lymphozyten sind sehr spärlich anzutreffen, Makrophagen finden sich nur fokal und in geringer Menge. Komplementablagerungen auf dem Sarkolemm von Muskelfasern oder Muskelfasernekrosen sind nicht erkennbar.

\section{Anti-SAE Autoantikörper-assoziierte DM}

Antikörper gegen Sumo activating enzyme (SAE-1/2; > Tab. 1B) werden bei weniger als $10 \%$ der Patienten mit DM gefunden und stehen für ein eher mildes Krankheitsbild. Hautveränderungen gehen der Myositis oft voraus. Interstitielle Lungenerkrankungen sowie eine Assoziation mit Malignomen sind selten, aber beschrieben [49].

\section{Morphologie}

Insgesamt ist die Morphologie nur milde pathologisch mit einer gering ausgeprägten perifaszikulären Pathologie, geringen Komplementablagerungen und entzündlichen lymphozytären Infiltraten, während perimysial diffus verteilt Makrophagen sichtbar sind [50].

Zusammengefasst ist die perifaszikuläre Atrophie/Hypotrophie von Muskelfasern das einende morphologische Element der DM. Diese Atrophie lässt sich durch verschiedene Färbungen von MHC Klasse-I, CD56 und neonatalem Myosin bestätigen. Das Ausmaß der Atrophie ist jedoch sehr variabel. Komplementablagerungen auf dem Sarkolemm treten bei akuten Verläufen mit hohen CKWerten besonders stark auf. Eigene Beobachtungen zeigen, dass milde Krankheitsverläufe weniger Komplementablagerungen aufweisen.

Bei anti-TIF1y-assoziierten DM-Fällen ist die kapilläre Komplementablagerung hinweisend auf maligne Verläufe. Alle DM-Subentitäten zeigen ultrastrukturell undulierende Tubuli als Zeichen einer frühen Kapillarschädigung.

Die ISG15- und Myxovirus A (MxA)- Färbung gilt als hilfreicher Gewebsbiomarker zur Identifikation einer DM - auch in Abgrenzung zu anderen Entitäten die ebenfalls MHC Klasse-I positive Fasern oder auch eine perifaszikuläre Atrophie zeigen.

\section{Immunmediierte nekrotisierende Myopathien (IMNM)}

\section{Klinik}

Die typische klinische Erstmanifestation sowohl bei anti-„,Signal recognition Particle“(SRP)- als auch bei anti-Hydroxy-Methylgluta- 

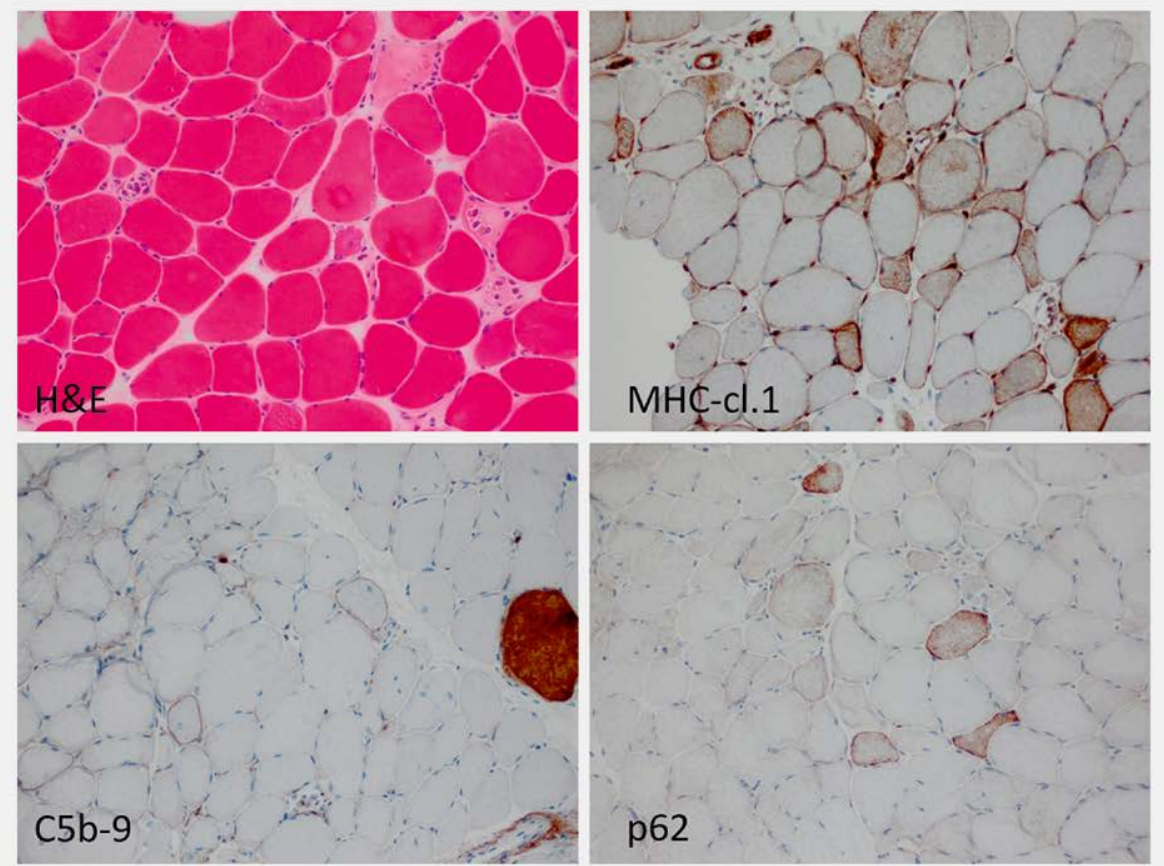

- Abb. 2 Histologie bei IMNM.

ryl-CoA-Reductase-(HMGCR-)AK-positiven Patienten sind subakut einsetzende proximale Paresen v. a. der unteren Extremität. Bei anti-SRP-Antikörper-positiven Patienten treten selten ILD und kardiale Probleme hinzu [51]. Patienten mit anti-HMGCR Autoantikörpern sind meist „pure“ Myositis-Patienten. Es sei jedoch hervorgehoben, dass bei ca. 20\% der HMGCR Patienten mit Malignomen gerechnet werden muss, während diese Assoziation für antiSRP + Patienten bislang nicht beschrieben wurde [7] .

Neben diesen typischen subakuten Verläufen gibt es jedoch die sogenannten pseudo-dystrophischen Verläufe, bei denen sich Patienten über viele Jahre sehr langsam verschlechtern und die daher eine besondere differentialdiagnostische Herausforderung darstellen [52]. Mit etwa 50\% der Patienten hat ein erheblicher Anteil nach vier Jahren Therapie keine zufriedenstellende Muskelkraft, vor allem farbige Patienten zeigten ein schlechtes Outcome [53]. Bei anti-HMGCGR Antikörper-positiven Patienten ist eine Assoziation zum HLA-Klasse II Antigen DRB1 * 11:01, bei asiatischen Patienten mit anti-SRP Antikörpern ist eine Assoziation mit DRB1 * 08:03 und DRB1 * 14:03 beschrieben.

\section{Labor}

IMNM-Patienten weisen in typischen Fällen hohe CK mit etwa bis zu 10000 IU/I auf. Die CK Werte korrelieren gut mit Krankheitsaktivität und Therapieverlauf bzw. -erfolg. SowohI SRP- als auch HMG CoA-AK korrelieren in der Titerhöhe mit der Krankheitsaktivität [51]. Aus lizenrechtlichen Gründen sind HMGCoA-AK nicht Teil kommerzieller Myositisblots, sondern müssen separat bestimmt werden.

\section{Morphologie}

Die typischen Veränderungen, welche sich bei der IMNM finden, lassen sich in vier Kategorien einteilen [51] ( über typische Histologie aller IIM s. a. > Tab. 3 )

Muskelfasernekrosen sind diffus verteilt und somit nicht an eine spezifische lokale Muskelregion gebunden. Die Anzahl der Muskeleinzelfasernekrosen variiert beträchtlich und Regenerate mit diffuser Verteilung können auffälliger als die Nekrosen sein.

Nekrosen im Gewebe lassen sich nicht als Gewebsbiomarker heranziehen, sie kommen bei vielen Erkrankungen anderen Ursprungs ebenfalls vor.

Makrophagen stellen bei weitem die größte Population der Entzündungszellen dar. Sie sind diffus im Endomysium und Perimysium verteilt und auch an dem Einzelfaseruntergang in Form von sog. Myophagozytosen beteiligt. Lymphozytäre Infiltrate sind weniger prominent. Sie lagern sich um Gefäße an oder liegen vereinzelt im Endo- bzw. Perimysium. Jedoch invadieren die CD8 + T-Zellen nicht speziell die Muskelfasern. MHC Klasse-I positive Zellen lassen sich auf dem Sarkolemm nachweisen (Abb 2), jedoch keine MHC Klasse-II Zellen. Ebenso wechselnd kräftig finden sich sarkolemmale granulär imponierende Komplementablagerungen.

Mit Autophagiemarkern wie LC3 und p62 lässt sich das Sarkolemm von einigen Fasern homogen und feingranulär (nicht grob wie bei IBM) anfärben [54].

Die sarkoplasmatische feingranuläre Anfärbung mit p62 Antikörpern lässt sich im Kontext der genannten weiteren Veränderungen sehr gut als Gewebsbiomarker für die IMNM nutzen. 
- Tab 3 typische histologische Befunde bei DM, IBM, IMNM, ASS.

\begin{tabular}{|c|c|c|c|c|}
\hline & DM/jDM & IBM & IMNM & ASS \\
\hline $\begin{array}{l}\text { Morphologische } \\
\text { Merkmale }\end{array}$ & $\begin{array}{l}\text { Infiltrate: perimysiale und } \\
\text { manchmal perivaskuläre } \\
\text { Rundzellinfilltrate aus } \\
\text { Lympho-monozytären } \\
\text { Zellelementen Gefäße: } \\
\text { Komplementablagerung auf } \\
\text { Kapillarendothelien oder } \\
\text { sarkolemmal Muskelfasern: } \\
\text { perifaszikuläre Atrophie }\end{array}$ & $\begin{array}{l}\text { Infiltrate: endomysiales } \\
\text { Rundzellinfiltrat mit } \\
\text { Assoziation zu und Invasion } \\
\text { von Muskelfasern Gefäße: } \\
\text {-Muskelfasern: Myodegenera- } \\
\text { tion mit Faseratrophien, } \\
\text { geränderten Vakuolen } \\
\text { („rimmed vacuoles“) } \\
\text { mitochondriale Veränderun- } \\
\text { gen Bindegewebe: deutliche } \\
\text { Fibrose und fettgewebiger } \\
\text { Umbau (chronisch) }\end{array}$ & $\begin{array}{l}\text { Infiltrate: milde } \\
\text { T-Zell-Infiltration im } \\
\text { Endomysium 7Muskel- } \\
\text { fasern: diffus verteilte } \\
\text { Einzelfasernekrosen } \\
\text { Bindegewebe: akut nicht } \\
\text { wesentlich verändert bei } \\
\text { chronischen Verläufen } \\
\text { deutliche Fibrose } \\
\text { endomysial }\end{array}$ & $\begin{array}{l}\text { Infiltrate: perimysiale } \\
\text { Rundzellinfilltrate aus } \\
\text { Lympho-monozytären } \\
\text { Zellelementen Komplement- } \\
\text { ablagerung sarkolemmal } \\
\text { Muskelfasern: perifaszikulär } \\
\text { nekrotische Fasern Bindegewe- } \\
\text { be: verbreitert fragmentiertes } \\
\text { Perimysium }\end{array}$ \\
\hline Immunhistologie & $\begin{array}{l}\text { Infiltrate: selten CD20 } \\
\text { B-Zellen Makrophagen, } \\
\text { T-Zellen Gefäße: Komple- } \\
\text { mentablagerungen (Tif1Y } \\
\text { und NXP) sarkolemmale } \\
\text { Komplementablagerung bei } \\
\text { Mi-2 Muskelfasern: MHC-I } \\
\text { und MxA perifaszikulär } \\
\text { MHC-II sarkolemmal negativ } \\
\text { bis allenfalls ganz gering }\end{array}$ & $\begin{array}{l}\text { Infiltrate: CD8 > CD4 T-Zellen, } \\
\text { Makrophagen, Assoziation } \\
\text { und Invasion von CD8 T-Zellen } \\
\text { in MHC-I exprimierende } \\
\text { intakte Muskelfasern } \\
\text { Muskelfasern: MHC-I und -II } \\
\text { ubiquitär mit fokaler } \\
\text { Betonung TDP43 und p62 } \\
\text { positive grobe Ablagerungen } \\
\text { in Vakuolen }\end{array}$ & $\begin{array}{l}\text { Infiltrate: Makrophagen } \\
\text { fokal T Zellen Muskel- } \\
\text { fasern: Muskelfasernekro- } \\
\text { sen, Regenerate, } \\
\text { Myophagozytosen } \\
\text { Gefäße: verbreitert keine/ } \\
\text { selten Komplementabla- } \\
\text { gerungen, Fasen } \\
\text { sarkoplasmatisch fein } \\
\text { granulär p62+ }\end{array}$ & $\begin{array}{l}\text { Infiltrate: reichlich perimysiale } \\
\text { Makrophagen, T-Zellen betont } \\
\text { im Perimysium nach endomysi- } \\
\text { al reichend Gefäße: Kapillaren } \\
\text { verdickt aber keine relevanten } \\
\text { Komplementablagerungen } \\
\text { sarkolemmale Komplementab- } \\
\text { lagerung betont perifszikulär } \\
\text { Muskelfasern: MHC-I und } \\
\text { MHC-II sarkolemmal oft mit } \\
\text { perifaszikulärer Betonung }\end{array}$ \\
\hline
\end{tabular}

\section{Anti-Synthetase Syndrom (ASS)}

Das Anti-Synthetase Syndrom (ASS) ist eine Krankheitsentität, die serologisch durch das Vorhandensein eines der Autoantikörper gegen tRNA-Synthetasen definiert ist.

Der häufigste AK in dieser Gruppe ist der anti-Jo1-Antikörper, während Antikörper gegen PL-7 und PL-12-seltener sind, und AK gegen EJ-, OJ-, KS-, Ha-, Zo- eher eine Rarität darstellen.

Klinisch bestehen neben myopathischen Beschwerden kombiniert mit einer interstitiellen Lungenerkrankung in wechselnder Dominanz des einen oder anderen Symptoms auch Fieber, Raynaud-Syndrom, seronegative Arthritiden, Serositiden und Hautveränderungen, hier besonders häufig sogenannte „Mechanikerhände“ oder „-füße“.

ASS-AK stellen sich in der IIF überwiegend zytoplamatisch dar, ebenso begleitend auftretende Ro-52 AK, die mit schwerem Verlauf bzw. paradoxerweise gutem Therapieansprechen bei interstitieller Lungenbeteiligung assoziiert sind.

Es kann im Verlauf intraindividuell zu einer erheblichen Dissoziation von Krankheitsmanifestationen insbesondere interstitieller Lungenerkrankung und Myositis kommen [8, 55-57].

\section{Morphologie}

Bei den Myositiden i.R. der ASS handelt es sich histomorphologisch um eine eigenständige Entität [8,50,55-57]. Hier findet man perifaszikulär gelegene Muskelfasernekrosen und eine typische perimysiale Bindegewebs-fragmentierung, die sich am eindrücklichsten in der Alkalischen Phosphatase-Färbung (s. Abb 4) zeigt [8, 5658]. Im Perimysium finden sich dichte lymphomonozytäre Infiltrate bestehend aus B Zellen, Plasmazellen und T Zellen. Ein hilfreiches Merkmal sind die MHC Klasse I- und Klasse II-Färbungen der perifaszikulären Region, die in zentrofaszikulärer Richtung an Intensität abnehmen. Komplementablagerungen finden sich vor allem in der perifaszikulären Region auf den Fasern sarkolemmal, nicht aber relevant auf den Kapillaren [55, 56] . Elektronenmikroskopisch zeigen sich in etwa $70 \%$ der ASS-Biopsate myonukleäre Actin-Filamente, die bei anderen Myositiden nicht vorhanden sind [56].

\section{Sporadische Einschlußkörpermyositis (sIBM)}

Klinik

Klinisch besteht bei den meist über 50 -jährigen Patienten eine Trias aus Quadrizepsparesen, Paresen der langen Fingerbeuger und Schluckdefiziten [59].

Auch wenn die Ätiologie der Erkrankung bis heute ungeklärt ist, wurden Teilaspekte intensiv beleuchtet. Hierzu gehören inflammatorische, degenerative, neoplastische und [25,59-65] genetische Aspekte [25, 59-65].

Labor

Bei moderater Sensitivität, aber hoher Spezifität haben Mup44(Synonym CN1A; NT5C1A) AK-positive Patienten oft klinisch schwerere Verläufe der IBM als AK-negative Patienten [66].

Die CK ist bei der Erkrankung nur moderat erhöht und eignet sich nicht gut zur Beurteilung des Langzeitverlaufes bzw. der Krankheitsaktivität. Die Erkrankung tritt ausschließlich im Erwachsenenalter auf. Patienten in jüngerem Alter sollten auf eine HIV-Infektion untersucht werden. Meist ist jedoch die HIV-Erkrankung bei der HIV-assoziierten IBM bereits lange bekannt. 
Die IBM kann in seltenen Fällen in Kombination mit Kollagenosen (z. B. Sjögren-Syndrom) auftreten.

\section{Morphologie}

Die morphologische Diagnose bei der IBM ist meist eindeutig, wenn die nachfolgend beschriebenen vier Komponenten in der Muskelbiopsie identifiziert werden können i) Eine spezifische CD8 + - lymphozytäre, inflammatorische Komponente kombiniert mit kräftiger MHC-Klasse-I- und -II-Färbung der Fasermembranen, ii) eine degenerative Komponente, die durch die geränderten Vakuolen und durch einen autophagischen Proteinabbau gekennzeichnet ist (z. B. p62, LC3, TDP43 etc.) und den Nachweis von amyloidogenen Proteinen, und/oder tubulofilamentären Strukturen in Myonuklei oder in Vakuolen, iii) eine mitochondriale Komponente mit Nachweis von COX-negativen SDH-positiven Fasern und parakristallinen Einschlüssen in Mitochondrien, sowie iv) ein schwer myopathischdystroph verändertes Gewebsbild mit Muskelfasernekrosen und endomysialer Fibrose.

Polymyositis (PM)

Das Konzept der PM, definiert durch endomysiale entzündliche Infiltrate und Invasion von Lymphozyten in nicht nekrotische Muskelfasern ohne sarkoplasmatische 'rimmed vacuoles', wurde in den letzten Jahrzehnten intensiv, klinisch [67-70], und histomorphologisch [71-73] hinterfragt. Postuliert wird, dass die PM insgesamt sehr selten ist und/oder, dass die PM eine frühe Form der sIBM darstellt [72]. Die Diagnose einer PM wird somit mehr und mehr zu einer Ausschlussdiagnose, da wahrscheinlich eine Vielzahl von Erkrankungen hierunter subsummiert werden, die sich aktuell nicht zuordnen lassen. Hierzu gehören die (frühe) sIBM, [70, 72, die bereits erwähnte 'Unspezifische Myositis' oder die sog. 'Overlap Myositis' (s.u.) [73]. Auch hereditäre Myopathien sollten in diesem Kontext ausgeschlossen werden [74].

\section{Overlap-Myositis/Unspezifische Myositis}

Für den sowohl in den Klassifikationsdiskussionen als auch im klinischen Alltag häufig verwendeten Begriff „Overlap-Myositis“ gibt es aktuell kein spezifisches histomorphologisches Korrelat.

Daher wird alternativ auch der Begriff der 'non-specified myositis' [70] benutzt, wobei histologisch die Kriterien für eine DM, PM oder IBM nicht erfüllt sind. Morphologisch wurden inflammatorische Veränderungen in überwiegend perimysialer und perivaskulärer Lage, bestehend aus mononukleären Zellen ohne endomysial gelegene Zellen und ohne perifaszikuläre Atrophie beschrieben [70]. Die meisten dieser Patienten litten bei Nachbeobachtung unter einer (ev. undifferenzierten) Kollagenose unter oftmaliger Anwesenheit von MSA.

\section{Zusammenfassung}

Neben der Erweiterung der Kenntnisse um Myositis-spezifische Antikörper, die vorbestehende Diskussionen um die Praktikabilität bekannter Klassifikationskriterien neu entfacht und die spezifische Zuordnung zu Subentitäten ermöglicht haben, trägt auch das deutlich gewachsene Wissen um entitätsspezifische Immunsignaturen wie Typ-I IFN bei DM oder ultrastrukturelle Veränderungen in der Myopathologie, sowohl zum Verständnis der Pathogenese, als auch zur intraindividuellen Therapieentscheidung und -steuerung bei. Neben ,klassischen' Serumbiomarkern (CK usw.) haben sich Gewebsbiomarker (MxA, ISG15), welche die Aktivität der Interferonsignatur unterstreichen, etabliert.

Diese lassen sich womöglich in der nahen Zukunft auch mit Serumbiomarkern aus derselben Kategorie (Typ-I IFN) kombinieren. Autoantikörper haben einen hohen prognostischen Wert für bestimmte Krankheitsverläufe und können formal somit auch als Biomarker gesehen werden. Die Sensitivität und Spezifität der verfügbaren Myositis-Blots hat sich in den letzten Jahren deutlich verbessert.

Interessenkonflikt

Die Autorinnen/Autoren geben an, dass kein Interessenkonflikt besteht.

Literatur

[1] Aggarwal R, Rider LG, Ruperto N et al. 2016 American College of Rheumatology/European League Against Rheumatism Criteria for Minimal, Moderate, and Major Clinical Response in Adult Dermatomyositis and Polymyositis: An International Myositis Assessment and Clinical Studies Group/Paediatric Rheumatology International Trials Organisation Collaborative Initiative. Arthritis Rheumatol 2017; 69: 898-910. doi:10.1002/art.40064

[2] Bassez G, Authier F], Lechapt-Zalcman E et al. Inflammatory myopathy with abundant macrophages (IMAM): a condition sharing similarities with cytophagic histiocytic panniculitis and distinct from macrophagic myofasciitis. J Neuropathol Exp Neurol 2003; 62: 464-474. doi:10.1093/jnen/62.5.464

[3] Olivier PA, De Paepe B, Aronica E et al. Idiopathic inflammatory myopathy: Interrater variability in muscle biopsy reading. Neurology 2019; 93: e889-e894. doi:10.1212/WNL.0000000000008005

[4] Pestronk A. Acquired immune and inflammatory myopathies: pathologic classification. Curr Opin Rheumatol 2011; 23: 595-604. doi:10.1097/BOR.0b013e32834bab42

[5] Tanboon J, Uruha A, Stenzel W et al. Where are we moving in the classification of idiopathic inflammatory myopathies? Curr Opin Neurol 2020; 33: 590-603. doi:10.1097/WCO.0000000000000855

[6] Troyanov Y, Targoff IN, Tremblay JL et al. Novel classification of idiopathic inflammatory myopathies based on overlap syndrome features and autoantibodies: analysis of 100 French Canadian patients. Medicine (Baltimore) 2005; 84: 231-249. doi:10.1097/01. md.0000173991.74008.b0

[7] Allenbach Y, Mammen AL, Benveniste $O$ et al. 224th ENMC International Workshop: Clinico-sero-pathological classification of immunemediated necrotizing myopathies Zandvoort, The Netherlands, 14-16 October 2016. Neuromuscul Disord 2018; 28: 87-99. doi:10.1016/j. nmd.2017.09.016

[8] Mescam-Mancini L, Allenbach Y, Hervier B et al. Anti-Jo-1 antibodypositive patients show a characteristic necrotizing perifascicular myositis. Brain 2015; 138: 2485-2492. doi:10.1093/brain/awv192

[9] Benveniste O, Goebel HH, Stenzel W. Biomarkers in Inflammatory Myopathies-An Expanded Definition. Front Neurol 2019; 10: 554. doi:10.3389/fneur.2019.00554

[10] George MD, McGill NK, Baker JF. Creatine kinase in the U.S. population: Impact of demographics, comorbidities, and body composition on the normal range. Medicine (Baltimore) 2016; 95 : e4344. doi:10.1097/MD.0000000000004344 
[11] Gono T, Sato S, Kawaguchi Y et al. Anti-MDA5 antibody, ferritin and IL-18 are useful for the evaluation of response to treatment in interstitial lung disease with anti-MDA5 antibody-positive dermatomyositis. Rheumatology (Oxford) 2012; 51: 1563-1570. doi:10.1093/rheumatology/kes102

[12] Wassie M, Lee MS, Sun BC et al. Single vs Serial Measurements of Cardiac Troponin Level in the Evaluation of Patients in the Emergency Department With Suspected Acute Myocardial Infarction. JAMA Netw Open 2021; 4: e2037930. doi:10.1001/jamanetworkopen.2020.37930

[13] Lilleker JB, Diederichsen ACP, Jacobsen S et al. Using serum troponins to screen for cardiac involvement and assess disease activity in the idiopathic inflammatory myopathies. Rheumatology (Oxford) 2018; 57: 1041-1046. doi:10.1093/rheumatology/key031

[14] Schmid J, Liesinger L, Birner-Gruenberger R et al. Elevated Cardiac Troponin T in Patients With Skeletal Myopathies. J Am Coll Cardiol 2018; 71: 1540-1549. doi:10.1016/j.jacc.2018.01.070

[15] Fathi M, Barbasso Helmers S, Lundberg IE. KL-6: a serological biomarker for interstitial lung disease in patients with polymyositis and dermatomyositis. J Intern Med 2012; 271: 589-597. doi:10.1111/j.1365-2796.2011.02459.x

[16] Betteridge Z, Tansley S, Shaddick G et al. Frequency, mutual exclusivity and clinical associations of myositis autoantibodies in a combined European cohort of idiopathic inflammatory myopathy patients. J Autoimmun 2019; 101: 48-55. doi:10.1016/j. jaut.2019.04.001

[17] Chan EK, Damoiseaux J, Carballo OG et al. Report of the First International Consensus on Standardized Nomenclature of Antinuclear Antibody HEp-2 Cell Patterns 2014-2015. Front Immunol 2015; 6: 412. doi:10.3389/fimmu.2015.00412

[18] Pinal-Fernandez I, Casal-Dominguez M, Derfoul A et al. Machine learning algorithms reveal unique gene expression profiles in muscle biopsies from patients with different types of myositis. Ann Rheum Dis 2020; 79: 1234-1242. doi:10.1136/annrheumdis-2019-216599

[19] Pinal-Fernandez I, Casal-Dominguez M, Derfoul A et al. Identification of distinctive interferon gene signatures in different types of myositis. Neurology 2019; 93: e1193-e1204. doi:10.1212/ WNL.0000000000008128

[20] Zhu W, Streicher K, Shen N et al. Genomic signatures characterize leukocyte infiltration in myositis muscles. BMC Med Genomics 2012; 5: 53. doi:10.1186/1755-8794-5-53

[21] Tang Y, Luo X, Cui H et al.. MicroRNA-146A contributes to abnormal activation of the type I interferon pathway in human lupus by targeting the key signaling proteins. Arthritis Rheum 2009; 60: 1065-1075. doi:10.1002/art.24436

[22] Acosta-Herrera M, Kerick M, Gonzalez-Serna D et al. Genome-wide meta-analysis reveals shared new loci in systemic seropositive rheumatic diseases. Ann Rheum Dis 2019; 78: 311-319. doi:10.1136/annrheumdis-2018-214127

[23] Rothwell S, Chinoy H, Lamb JA et al. Focused HLA analysis in Caucasians with myositis identifies significant associations with autoantibody subgroups. Ann Rheum Dis 2019; 78: 996-1002. doi:10.1136/annrheumdis-2019-215046

[24] Hoogendijk JE, Amato AA, Lecky BR et al. 119 th ENMC international workshop: trial design in adult idiopathic inflammatory myopathies, with the exception of inclusion body myositis, 10-12 October 2003, Naarden, The Netherlands. Neuromuscul Disord 2004; 14: 337-345. doi:10.1016/j.nmd.2004.02.006

[25] De Visser M, Emslie-Smith AM, Engel AG. Early ultrastructural alterations in adult dermatomyositis. Capillary abnormalities precede other structural changes in muscle. J Neurol Sci 1989; 94: 181-192. doi:10.1016/0022-510x(89)90228-1
[26] Greenberg SA, Pinkus JL, Pinkus GS et al. Interferon-alpha/ beta-mediated innate immune mechanisms in dermatomyositis. Ann Neurol 2005; 57: 664-678. doi:10.1002/ana.20464

[27] Liao AP, Salajegheh M, Nazareno R et al. Interferon beta is associated with type 1 interferon-inducible gene expression in dermatomyositis. Ann Rheum Dis 2011; 70: 831-836. doi:10.1136/ard.2010.139949

[28] Greenberg SA, Higgs BW, Morehouse C et al. Relationship between disease activity and type 1 interferon- and other cytokine-inducible gene expression in blood in dermatomyositis and polymyositis. Genes Immun 2012; 13: 207-213. doi:10.1038/gene.2011.61

[29] Higgs BW, Liu Z, White B et al. Patients with systemic lupus erythematosus, myositis, rheumatoid arthritis and scleroderma share activation of a common type I interferon pathway. Ann Rheum Dis 2011; 70: 2029-2036. doi:10.1136/ard.2011.150326

[30] Melki I, Devilliers H, Gitiaux C et al. Anti-MDA5 juvenile idiopathic inflammatory myopathy: a specific subgroup defined by differentially enhanced interferon-alpha signalling. Rheumatology (Oxford) 2020; 59: 1927-1937. doi:10.1093/rheumatology/kez525

[31] Pinal-Fernandez I, Casal-Dominguez M, Milisenda JC et al. Response to: 'Correspondence on 'Machine learning algorithms reveal unique gene expression profiles in muscle biopsies from patients with different types of myositis'” by Takanashi et al. Ann Rheum Dis 2021. doi:10.1136/annrheumdis-2020-219767

[32] Suarez-Calvet X, Gallardo E, Nogales-Gadea G et al. Altered RIG-I/ DDX58-mediated innate immunity in dermatomyositis. J Pathol 2014; 233: 258-268. doi:10.1002/path.4346

[33] Takanashi S. Correspondence on 'Machine learning algorithms reveal unique gene expression profiles in muscle biopsies from patients with different types of myositis'. Ann Rheum Dis 2020. doi:10.1136/ annrheumdis-2020-219677

[34] Greenberg SA. Type 1 interferons and myositis. Arthritis Res Ther 2010; 12: S4. doi:10.1186/ar2885

[35] Radke J, Koll R, Preusse C et al. Architectural B-cell organization in skeletal muscle identifies subtypes of dermatomyositis. Neurology(R) neuroimmunology \& neuroinflammation 2018; 5: e451. doi:10.1212/ NXI.0000000000000451

[36] Radke J, Koll R, Preuße C et al. Architectural B-cell organization in skeletal muscle identifies subtypes of dermatomyositis. 2018; 5: e451. doi:10.1212/NXI.0000000000000451\%] Neurology - Neuroimmunology Neuroinflammation

[37] Uruha A, Nishikawa A, Tsuburaya RS et al. Sarcoplasmic MxA expression: A valuable marker of dermatomyositis. Neurology 2017; 88: 493-500. doi:10.1212/WNL.0000000000003568

[38] Biesen R, Demir C, Barkhudarova F et al. Sialic acid-binding Ig-like lectin 1 expression in inflammatory and resident monocytes is a potential biomarker for monitoring disease activity and success of therapy in systemic lupus erythematosus. Arthritis Rheum 2008; 58 : 1136-1145. doi:10.1002/art.23404

[39] Lim J, Raaphorst J, van der Kooi AJ. Comment on "Systematic retrospective study on 64 patients anti-Mi2 dermatomyositis: A classic skin rash with a necrotizing myositis and high risk of malignancy". J Am Acad Dermatol 2020; 83: e459-e460. doi:10.1016/j. jaad.2020.06.1032

[40] Monseau G, Landon-Cardinal O, Stenzel W et al. Systematic retrospective study of 64 patients with anti-Mi2 dermatomyositis: A classic skin rash with a necrotizing myositis and high risk of malignancy. J Am Acad Dermatol 2020; 83: 1759-1763. doi:10.1016/j. jaad.2020.03.058

[41] Allenbach Y, Benveniste O, Goebel HH et al. Integrated classification of inflammatory myopathies. Neuropathol Appl Neurobiol 2017; 43: 62-81. doi:10.1111/nan. 12380 
[42] Ladislau L, Suarez-Calvet $X$, Toquet $S$ et al. JAK inhibitor improves type I interferon induced damage: proof of concept in dermatomyositis. Brain 2018; 141: 1609-1621. doi:10.1093/brain/awy105

[43] Dani L, Holmqvist M, Martinez MA et al. Anti-transcriptional intermediary factor 1 gamma antibodies in cancer-associated myositis: a longitudinal study. Clin Exp Rheumatol 2020; 38: 67-73

[44] Hida A, Yamashita T, Hosono Y et al. Anti-TIF1-gamma antibody and cancer-associated myositis: A clinicohistopathologic study. Neurology 2016; 87: 299-308. doi:10.1212| WNL.0000000000002863

[45] Fiorentino DF, Chung LS, Christopher-Stine L et al. Most patients with cancer-associated dermatomyositis have antibodies to nuclear matrix protein NXP-2 or transcription intermediary factor 1gamma. Arthritis Rheum 2013; 65: 2954-2962. doi:10.1002/art.38093

[46] Inoue M, Tanboon J, Hirakawa S et al. Association of Dermatomyositis Sine Dermatitis With Anti-Nuclear Matrix Protein 2 Autoantibodies. JAMA Neurol 2020; 77: 872-877. doi:10.1001/jamaneurol.2020.0673

[47] Pinal-Fernandez I, Casciola-Rosen LA, Christopher-Stine L et al. The Prevalence of Individual Histopathologic Features Varies according to Autoantibody Status in Muscle Biopsies from Patients with Dermatomyositis. J Rheumatol 2015; 42: 1448-1454

[48] Allenbach Y, Leroux $G$, Suarez-Calvet $X$ et al. Dermatomyositis With or Without Anti-Melanoma Differentiation-Associated Gene 5 Antibodies: Common Interferon Signature but Distinct NOS2 Expression. Am J Pathol 2016; 186: 691-700. doi:10.1016/j. ajpath.2015.11.010

[49] Betteridge ZE, Gunawardena H, Chinoy H et al. Clinical and human leucocyte antigen class II haplotype associations of autoantibodies to small ubiquitin-like modifier enzyme, a dermatomyositis-specific autoantigen target, in UK Caucasian adult-onset myositis. Ann Rheum Dis 2009; 68: 1621-1625. doi:10.1136/ard.2008.097162

[50] Mammen AL, Allenbach Y, Stenzel W et al. 239th ENMC International Workshop: Classification of dermatomyositis, Amsterdam, the Netherlands, 14-16 December 2018. Neuromuscul Disord 2020; 30: 70-92. doi:10.1016/j.nmd.2019.10.005

[51] Allenbach Y, Benveniste O, Stenzel W et al. Immune-mediated necrotizing myopathy: clinical features and pathogenesis. Nat Rev Rheumatol 2020; 16: 689-701. doi:10.1038/s41584-020-00515-9

[52] Mohassel P, Landon-Cardinal O, Foley AR et al. Anti-HMGCR myopathy may resemble limb-girdle muscular dystrophy. Neurology $(\mathrm{R})$ neuroimmunology \& neuroinflammation 2019; 6: e523. doi:10.1212/nxi.0000000000000523

[53] Pinal-Fernandez I, Mammen AL. Spectrum of immune-mediated necrotizing myopathies and their treatments. Curr Opin Rheumatol 2016; 28: 619-624. doi:10.1097/BOR.0000000000000335

[54] Fischer N, Preusse C, Radke J et al. Sequestosome-1 (p62) expression reveals chaperone-assisted selective autophagy in immune-mediated necrotizing myopathies. Brain Pathol 2020; 30: 261-271. doi:10.1111/bpa.12772

[55] Aouizerate J, De Antonio M, Bassez G et al. Myofiber HLA-DR expression is a distinctive biomarker for antisynthetase-associated myopathy. Acta Neuropathol Commun 2014; 2: 154. doi:10.1186/ s40478-014-0154-2

[56] Stenzel W, Preusse C, Allenbach Y et al. Nuclear actin aggregation is a hallmark of anti-synthetase syndrome-induced dysimmune myopathy. Neurology 2015; 84: 1346-1354. doi:10.1212/ WNL.0000000000001422

[57] Uruha A, Suzuki S, Suzuki N et al. Perifascicular necrosis in anti-synthetase syndrome beyond anti-Jo-1. Brain 2016; 139: e50. doi:10.1093/brain/aww125
[58] Allenbach Y, Hervier B, Stenzel W et al. Reply: Perifascicular necrosis in anti-synthetase syndrome beyond anti-Jo-1. Brain 2016; 139: e51. doi:10.1093/brain/aww126

[59] Benveniste O, Stenzel W, Hilton-Jones D et al. Amyloid deposits and inflammatory infiltrates in sporadic inclusion body myositis: the inflammatory egg comes before the degenerative chicken. Acta Neuropathol 2015; 129: 611-624. doi:10.1007/s00401-015-1384-5

[60] Greenberg SA. Inclusion Body Myositis. Continuum (Minneap Minn) 2016; 22: 1871-1888. doi:10.1212/01.CON.0000511071.58338.1e

[61] Greenberg SA, Pinkus JL, Amato AA et al. Association of inclusion body myositis with $T$ cell large granular lymphocytic leukaemia. Brain 2016; 139: 1348-1360. doi:10.1093/brain/aww024

[62] Greenberg SA, Pinkus JL, Kong SW et al. Highly differentiated cytotoxic T cells in inclusion body myositis. Brain 2019; 142 : 2590-2604. doi:10.1093/brain/awz207

[63] Schmidt ], Dalakas MC. Inclusion body myositis: from immunopathology and degenerative mechanisms to treatment perspectives. Expert Rev Clin Immunol 2013; 9: 1125-1133. doi:10.1586/174466 6X.2013.842467

[64] Weihl CC, Mammen AL. Sporadic inclusion body myositis - a myodegenerative disease or an inflammatory myopathy. Neuropathol Appl Neurobiol 2017; 43: 82-91. doi:10.1111/nan.12384

[65] Zschuntzsch J, Voss J, Creus K et al. Provision of an explanation for the inefficacy of immunotherapy in sporadic inclusion body myositis: quantitative assessment of inflammation and beta-amyloid in the muscle. Arthritis Rheum 2012; 64: 4094-4103. doi:10.1002/ art.37692

[66] Goyal NA, Cash TM, Alam U et al. Seropositivity for NT5c1A antibody in sporadic inclusion body myositis predicts more severe motor, bulbar and respiratory involvement. J Neurol Neurosurg Psychiatry 2016; 87: 373-378. doi:10.1136/jnnp-2014-310008

[67] Amato AA, Griggs RC. Unicorns, dragons, polymyositis, and other mythological beasts. Neurology 2003; 61: 288-289. doi:10.1212/ wnl.61.3.288

[68] Bronner IM, Linssen WH, van der Meulen MF et al. Polymyositis: an ongoing discussion about a disease entity. Arch Neurol 2004; 61: 132-135. doi:10.1001/archneur.61.1.132

[69] Bronner IM, van der Meulen MF, de Visser M et al. Long-term outcome in polymyositis and dermatomyositis. Ann Rheum Dis 2006; 65: 1456-1461. doi:10.1136/ard.2005.045690

[70] van der Meulen MF, Bronner IM, Hoogendijk JE et al. Polymyositis: an overdiagnosed entity. Neurology 2003; 61: 316-321. doi:10.1212/ wnl.61.3.316

[71] Bronner IM, Hoogendijk JE, Veldman $\mathrm{H}$ et al. Tubuloreticular structures in different types of myositis: implications for pathogenesis. Ultrastruct Pathol 2008; 32: 123-126. doi:10.1080/01913120802209379

[72] Chahin N, Engel AG. Correlation of muscle biopsy, clinical course, and outcome in PM and sporadic IBM. Neurology 2008; 70: 418-424. doi:10.1212/01.wnl.0000277527.69388.fe

[73] Vilela VS, Prieto-Gonzalez S, Milisenda JC et al. Polymyositis, a very uncommon isolated disease: clinical and histological re-evaluation after long-term follow-up. Rheumatol Int 2015; 35: 915-920. doi:10.1007/s00296-014-3198-5

[74] Benveniste O, Romero NB. Myositis or dystrophy? Traps and pitfalls. Presse Med 2011; 40: e249-e255. doi:10.1016/j.lpm.2010.11.023

[75] Aggarwal R, Cassidy E, Fertig N et al. Patients with non-Jo-1 anti-tRNA-synthetase autoantibodies have worse survival than Jo-1 positive patients. Ann Rheum Dis 2014; 73: 227-232. doi:10.1136/ annrheumdis-2012-201800

[76] Alenzi FM. Myositis Specific Autoantibodies: A Clinical Perspective. Open Access Rheumatol 2020; 12: 9-14. doi:10.2147/OARRR. S231195 
[77] Bernstein RM, Morgan SH, Chapman J et al. Anti-Jo-1 antibody: a marker for myositis with interstitial lung disease. Br Med J (Clin Res Ed) 1984; 289: 151-152. doi:10.1136/bmj.289.6438.151

[78] Brouwer R, Hengstman G], Vree Egberts W et al. Autoantibody profiles in the sera of European patients with myositis. Ann Rheum Dis 2001; 60: 116-123. doi:10.1136/ard.60.2.116

[79] Mathews MB, Bernstein RM. Myositis autoantibody inhibits histidyl-tRNA synthetase: a model for autoimmunity. Nature 1983; 304: 177-179. doi:10.1038/304177a0

[80] Sharma A, Bhattarai D, Gupta A et al. Autoantibody Profile of Children with Juvenile Dermatomyositis. Indian J Pediatr 2021. doi:10.1007/s12098-021-03680-1

[81] Fujimoto M. [Myositis-specific autoantibodies]. Brain Nerve 2013; 65: 449-460

[82] Bunn CC, Bernstein RM, Mathews MB. Autoantibodies against alanyl-tRNA synthetase and tRNAAla coexist and are associated with myositis. J Exp Med 1986; 163: 1281-1291. doi:10.1084/ jem.163.5.1281

[83] Hirakata M, Suwa A, Nagai S et al. Anti-KS: identification of autoantibodies to asparaginyl-transfer RNA synthetase associated with interstitial lung disease. J Immunol 1999; 162: 2315-2320

[84] Silva MB, Silva MG, Shinjo SK. Serum hyaluronic acid in polymyositis: high serum levels tend to correlate with disease activity. Acta Reumatol Port 2014; 39: 248-253

[85] Betteridge Z, Gunawardena H, North J et al. Anti-synthetase syndrome: a new autoantibody to phenylalanyl transfer RNA synthetase (anti-Zo) associated with polymyositis and interstitial pneumonia. Rheumatology (Oxford) 2007; 46: 1005-1008. doi:10.1093/rheumatology/kem045

[86] Mahler M, Miller FW, Fritzler MJ. Idiopathic inflammatory myopathies and the anti-synthetase syndrome: a comprehensive review. Autoimmun Rev 2014; 13: 367-371. doi:10.1016/j.autrev.2014.01.022

[87] Chinoy $\mathrm{H}$, Li CK, Platt $\mathrm{H}$ et al.. Genetic association study of NF-kappaB genes in UK Caucasian adult and juvenile onset idiopathic inflammatory myopathy. Rheumatology (Oxford) 2012; 51: 794-799. doi:10.1093/rheumatology/ker379

[88] Klein M, Mann H, Plestilova L et al. Increasing incidence of immunemediated necrotizing myopathy: single-centre experience. Rheumatology (Oxford) 2015; 54: 2010-2014. doi:10.1093/ rheumatology/kev229

[89] Wichmann O, Yoon IK, Vong S et al. Dengue in Thailand and Cambodia: an assessment of the degree of underrecognized disease burden based on reported cases. PLoS Negl Trop Dis 2011; 5: e996. doi:10.1371/journal.pntd.0000996

[90] Padala S, Thompson PD. Statins as a possible cause of inflammatory and necrotizing myopathies. Atherosclerosis 2012; 222: 15-21. doi:10.1016/j.atherosclerosis.2011.11.005

[91] Asakawa K, Yoshizawa K, Aoki A et al. Comparison of cytokine profiles between anti-ARS antibody-positive interstitial lung diseases and those with anti-MDA-5 antibodies. Clin Rheumatol 2020; 39: 2171-2178. doi:10.1007/s10067-020-04984-x

[92] DeWane ME, Waldman R, Lu J. Dermatomyositis: Clinical features and pathogenesis. J Am Acad Dermatol 2020; 82: 267-281. doi:10.1016/j.jaad.2019.06.1309

[93] Peisley A, Lin C, Wu B et al. Cooperative assembly and dynamic disassembly of MDA5 filaments for viral dsRNA recognition. Proc Natl Acad Sci U S A 2011; 108: 21010-21015. doi:10.1073/ pnas. 1113651108

[94] Sato S, Hoshino K, Satoh T et al. RNA helicase encoded by melanoma differentiation-associated gene 5 is a major autoantigen in patients with clinically amyopathic dermatomyositis: Association with rapidly progressive interstitial lung disease. Arthritis Rheum 2009; 60: 2193-2200. doi:10.1002/art.24621
[95] Takada T, Aoki A, Asakawa K et al. Serum cytokine profiles of patients with interstitial lung disease associated with anti-CADM-140/MDA5 antibody positive amyopathic dermatomyositis. Respir Med 2015; 109: 1174-1180. doi:10.1016/j.rmed.2015.07.004

[96] Targoff IN, Reichlin M. The association between Mi-2 antibodies and dermatomyositis. Arthritis Rheum 1985; 28: 796-803. doi:10.1002/ art. 1780280711

[97] Gunawardena H, Wedderburn LR, Chinoy $\mathrm{H}$ et al. Autoantibodies to a $140-k d$ protein in juvenile dermatomyositis are associated with calcinosis. Arthritis Rheum 2009; 60: 1807-1814. doi:10.1002/ art. 24547

[98] Ichimura Y, Matsushita T, Hamaguchi Y et al. Anti-NXP2 autoantibodies in adult patients with idiopathic inflammatory myopathies: possible association with malignancy. Ann Rheum Dis 2012; 71: 710-713. doi:10.1136/annrheumdis-2011-200697

[99] Merlo G, Clapasson A, Cozzani E et al. Specific autoantibodies in dermatomyositis: a helpful tool to classify different clinical subsets. Arch Dermatol Res 2017; 309: 87-95. doi:10.1007/s00403-0161704-1

[100] Nistala K, Wedderburn LR. Update in juvenile myositis. Curr Opin Rheumatol 2013; 25: 742-746. doi:10.1097/01. bor.0000434674.62644.02

[101] Targoff IN. Myositis specific autoantibodies. Curr Rheumatol Rep 2006; 8: 196-203. doi:10.1007/s11926-996-0025-3

[102] Betteridge ZE, Gunawardena H, McHugh NJ. Pathogenic mechanisms of disease in myositis: autoantigens as clues. Curr Opin Rheumatol 2009; 21: 604-609. doi:10.1097/BOR.0b013e328331638a

[103] Ghirardello A, Bassi N, Palma L et al. Autoantibodies in polymyositis and dermatomyositis. Curr Rheumatol Rep 2013; 15: 335. doi:10.1007/s11926-013-0335-1

[104] Reeves WH, Nigam SK, Blobel G. Human autoantibodies reactive with the signal-recognition particle. Proc Natl Acad Sci U S A 1986; 83 : 9507-9511. doi:10.1073/pnas.83.24.9507

[105] Betteridge Z, McHugh N. Myositis-specific autoantibodies: an important tool to support diagnosis of myositis. J Intern Med 2016; 280: 8-23. doi:10.1111/joim. 12451

[106] De Vooght J, Vulsteke JB, De Haes P et al. Anti-TIF1-gamma autoantibodies: warning lights of a tumour autoantigen. Rheumatology (Oxford) 2020; 59: 469-477. doi:10.1093/rheumatology/kez572

[107] Amlani A, Choi MY, Tarnopolsky M et al. Anti-NT5c1A Autoantibodies as Biomarkers in Inclusion Body Myositis. Front Immunol 2019; 10: 745. doi:10.3389/fimmu.2019.00745

[108] Herbert MK, Stammen-Vogelzangs ], Verbeek MM et al. Disease specificity of autoantibodies to cytosolic 5'-nucleotidase $1 \mathrm{~A}$ in sporadic inclusion body myositis versus known autoimmune diseases. Ann Rheum Dis 2016; 75: 696-701. doi:10.1136/annrheumdis-2014-206691

[109] Lloyd TE, Christopher-Stine L, Pinal-Fernandez I et al. Cytosolic 5'-Nucleotidase 1A As a Target of Circulating Autoantibodies in Autoimmune Diseases. Arthritis Care Res (Hoboken) 2016; 68: 66-71. doi:10.1002/acr.22600

[110] Yeker RM, Pinal-Fernandez I, Kishi T et al. Anti-NT5C1A autoantibodies are associated with more severe disease in patients with juvenile myositis. Ann Rheum Dis 2018; 77: 714-719. doi:10.1136/ annrheumdis-2017-212436

[111] Belizna C, Henrion D, Beucher A et al. Anti-Ku antibodies: Clinical, genetic and diagnostic insights. Autoimmun Rev 2010; 9: 691-694. doi:10.1016/j.autrev.2010.05.020

[112] Lakota K, Thallinger GG, Sodin-Semrl S et al. International cohort study of 73 anti-Ku-positive patients: association of p70/p80 anti-Ku antibodies with joint/bone features and differentiation of disease populations by using principal-components analysis. Arthritis Res Ther 2012; 14: R2. doi:10.1186/ar3550 
[113] Mimori T, Ohosone $\mathrm{Y}$, Hama $\mathrm{N}$ et al. Isolation and characterization of cDNA encoding the 80-kDa subunit protein of the human autoantigen $\mathrm{Ku}(\mathrm{p} 70 / \mathrm{p} 80)$ recognized by autoantibodies from patients with scleroderma-polymyositis overlap syndrome. Proc Natl Acad Sci U S A 1990; 87: 1777-1781. doi:10.1073/pnas.87.5.1777

[114] Brouwer R, Pruijn G], van Venrooij WJ. The human exosome: an autoantigenic complex of exoribonucleases in myositis and scleroderma. Arthritis Res 2001; 3: 102-106. doi:10.1186/ar147

[115] Brouwer R, Vree Egberts WT, Hengstman G] et al. Autoantibodies directed to novel components of the PM/Scl complex, the human exosome. Arthritis Res 2002; 4: 134-138. doi:10.1186/ar389

[116] De Lorenzo R, Pinal-Fernandez I, Huang W et al. Muscular and extramuscular clinical features of patients with anti-PM/Scl autoantibodies. Neurology 2018; 90: e2068-e2076. doi:10.1212/ WNL.0000000000005638

[117] Lega JC, Fabien N, Reynaud Q et al. The clinical phenotype associated with myositis-specific and associated autoantibodies: a meta-analysis revisiting the so-called antisynthetase syndrome. Autoimmun Rev 2014; 13: 883-891. doi:10.1016/j.autrev.2014.03.004

[118] Larman HB, Salajegheh M, Nazareno R et al. Cytosolic 5'-nucleotidase $1 \mathrm{~A}$ autoimmunity in sporadic inclusion body myositis. Ann Neurol 2013; 73: 408-418. doi:10.1002/ana.23840

[119] Salajegheh M, Lam T, Greenberg SA. Autoantibodies against a $43 \mathrm{KDa}$ muscle protein in inclusion body myositis. PLoS One 2011; 6: e20266. doi:10.1371/journal.pone.0020266

[120] Salajegheh M, Pinkus JL, Taylor JP et al. Sarcoplasmic redistribution of nuclear TDP-43 in inclusion body myositis. Muscle Nerve 2009; 40: 19-31. doi:10.1002/mus.21386

[121] Stuhlmuller B, Feist E, Haupl T et al. [New aspects on the pathogenesis of myositis]. Z Rheumatol 2013; 72: 209-219. doi:10.1007| s00393-012-1078-5

[122] Stuhlmuller B, Jerez R, Hausdorf $G$ et al. Novel autoantibodies against muscle-cell membrane proteins in patients with myositis. Arthritis Rheum 1996; 39: 1860-1868. doi:10.1002/art.1780391112

[123] Stuhlmuller B, Schneider U, Gonzalez-Gonzalez JB et al. Disease Specific Autoantibodies in Idiopathic Inflammatory Myopathies. Front Neurol 2019; 10: 438. doi:10.3389/fneur.2019.00438

[124] Bilazarian SD, Taylor AJ, Brezinski D et al. High-grade atrioventricular heart block in an adult with systemic lupus erythematosus: the association of nuclear RNP (U1 RNP) antibodies, a case report, and review of the literature. Arthritis Rheum 1989; 32: 1170-1174. doi:10.1002/anr.1780320918

[125] Casal-Dominguez M, Pinal-Fernandez I, Corse AM et al. Muscular and extramuscular features of myositis patients with anti-U1-RNP autoantibodies. Neurology 2019; 92: e1416-e1426. doi:10.1212/ WNL.0000000000007188

[126] Mimori T, Hinterberger M, Pettersson I et al. Autoantibodies to the U2 small nuclear ribonucleoprotein in a patient with sclerodermapolymyositis overlap syndrome. J Biol Chem 1984; 259: 560-565

[127] Rober N, Rejzek M, Aringer M et al. Multiparametric Analysis of Connective Tissue Disease Specific Autoantibodies Using a Spot Immunoassay. Clin Lab 2019; 65. doi:10.7754/Clin.Lab.2019.190218

[128] Wesner N, Uruha A, Suzuki S et al. Anti-RNP antibodies delineate a subgroup of myositis: A systematic retrospective study on 46 patients. Autoimmun Rev 2020; 19: 102465. doi:10.1016/j. autrev.2020.102465

[129] Bachmann M, Hilker M, Grolz D et al. Different La/SS-B mRNA isoforms are expressed in salivary gland tissue of patients with primary Sjogren's syndrome. J Autoimmun 1996; 9: 757-766. doi:10.1006/ jaut.1996.0098

[130] Beckman KA, Luchs J, Milner MS et al. The Potential Role for Early Biomarker Testing as Part of a Modern, Multidisciplinary Approach to Sjogren's Syndrome Diagnosis. Adv Ther 2017; 34: 799-812. doi:10.1007/s12325-017-0501-3
[131] Li JM, Horsfall AC, Maini RN. Anti-La (SS-B) but not anti-Ro52 (SS-A) antibodies cross-react with laminin--a role in the pathogenesis of congenital heart block? Clin Exp Immunol 1995; 99: 316-324. doi:10.1111/j.1365-2249.1995.tb05552.x

[132] Manthorpe R, Teppo AM, Bendixen G et al. Antibodies to SS-B in chronic inflammatory connective tissue diseases. Relationship with HLA-Dw2 and HLA-Dw3 antigens in primary Sjogren's syndrome. Arthritis Rheum 1982; 25: 662-667. doi:10.1002/art.1780250609

[133] Teppo AM, Gripenberg M, Kurki P et al. Purification and characterization of a nuclear SS-B antigen. Scand J Immunol 1982; 15: 1-7. doi:10.1111/j.1365-3083.1982.tb00615.x

[134] Arnett FC, Targoff IN, Mimori T et al. Interrelationship of major histocompatibility complex class II alleles and autoantibodies in four ethnic groups with various forms of myositis. Arthritis Rheum 1996; 39: 1507-1518. doi:10.1002/art.1780390910

[135] Chung SH, Bent El, Weiss MD et al. Sporadic inclusion body myositis and primary Sjogren's syndrome: an overlooked diagnosis. Clin Rheumatol 2021. doi:10.1007/s10067-021-05740-5

[136] Isenberg D, Cambridge J, Maddison PJ. Prevalence of Ro (SS-A) antibodies in patients with polymyositis. Arthritis Rheum 1987; 30: 1320. doi:10.1002/art.1780301124

[137] La Corte R, Lo Mo Naco A, Locaputo A et al. In patients with antisynthetase syndrome the occurrence of anti-Ro/SSA antibodies causes a more severe interstitial lung disease. Autoimmunity 2006; 39: 249-253. doi:10.1080/08916930600623791

[138] Ohashi K, Sada KE, Nakai Y et al. Cluster Analysis Using Anti-Aminoacyl-tRNA Synthetases and SS-A/Ro52 antibodies in Patients With Polymyositis/Dermatomyositis. J Clin Rheumatol 2019; 25: 246-251. doi:10.1097/RHU.0000000000000836

[139] Ghannam K, Martinez-Gamboa L, Spengler L et al. Upregulation of immunoproteasome subunits in myositis indicates active inflammation with involvement of antigen presenting cells, CD8 T-cells and IFNGamma. PLoS One 2014; 9: e104048. doi:10.1371/journal. pone. 0104048

[140] Houtman M, Ekholm L, Hesselberg E et al. T-cell transcriptomics from peripheral blood highlights differences between polymyositis and dermatomyositis patients. Arthritis Res Ther 2018; 20: 188. doi:10.1186/s13075-018-1688-7

[141] Li L, Chen S, Wen X et al. Positive Association between ANKRD55 Polymorphism 7731626 and Dermatomyositis/Polymyositis with Interstitial Lung Disease in Chinese Han Population. Biomed Res Int 2017; 2017: 2905987. doi:10.1155/2017/2905987

[142] Ugidos N, Mena J, Baquero S et al. Interactome of the Autoimmune Risk Protein ANKRD55. Front Immunol 2019; 10: 2067. doi:10.3389/ fimmu.2019.02067

[143] Jiang T, Huang Y, Liu H et al. Reduced miR-146a Promotes REG3A Expression and Macrophage Migration in Polymyositis and Dermatomyositis. Front Immunol 2020; 11: 37. doi:10.3389/fimmu.2020.00037

[144] Jinnin M. Recent progress in studies of miRNA and skin diseases. J Dermatol 2015; 42: 551-558. doi:10.1111/1346-8138.12904

[145] Kinder TB, Heier CR, Tully CB et al. Muscle Weakness in Myositis: MicroRNA-Mediated Dystrophin Reduction in a Myositis Mouse Model and Human Muscle Biopsies. Arthritis Rheumatol 2020; 72: 1170-1183. doi:10.1002/art.41215

[146] Gao X, Han L, Yuan L et al. HLA class II alleles may influence susceptibility to adult dermatomyositis and polymyositis in a Han Chinese population. BMC Dermatol 2014; 14: 9. doi:10.1186/1471. 5945-14-9

[147] Miller FW, Chen W, O'Hanlon TP et al. Genome-wide association study identifies HLA 8.1 ancestral haplotype alleles as major genetic risk factors for myositis phenotypes. Genes Immun 2015; 16 : 470-480. doi:10.1038/gene.2015.28 
[148] Remuzgo-Martinez S, Atienza-Mateo B, Ocejo-Vinyals JG et al. HLA association with the susceptibility to anti-synthetase syndrome. Joint Bone Spine 2020; 88: 105115. doi:10.1016/j.jbspin.2020.105115

[149] Rothwell S, Cooper RG, Lundberg IE et al. Dense genotyping of immune-related loci in idiopathic inflammatory myopathies confirms HLA alleles as the strongest genetic risk factor and suggests different genetic background for major clinical subgroups. Ann Rheum Dis 2016; 75: 1558-1566. doi:10.1136/annrheumdis-2015-208119

[150] Peng QL, Lin JM, Zhang YB et al. Targeted capture sequencing identifies novel genetic variations in Chinese patients with idiopathic inflammatory myopathies. Int J Rheum Dis 2018; 21: 1619-1626. doi:10.1111/1756-185X.13350

[151] Zhang J, Khasanova E, Zhang L. Bioinformatics analysis of gene expression profiles of Inclusion body myositis. Scand J Immunol 2020; 91: e12887. doi:10.1111/sji.12887
[152] Lazzaroni MG, Marasco E, Campochiaro C et al. The clinical phenotype of Systemic Sclerosis patients with anti-PM/Scl antibodies: results from the EUSTAR cohort. Rheumatology (Oxford) 2021. doi:10.1093/rheumatology/keab152

[153] Zanframundo G, Tripoli A, Cometi L et al. One year in review 2020: idiopathic inflammatory myopathies. Clin Exp Rheumatol 2021; 39: $1-12$

[154] Barsotti S, Bruni C, Cometi L et al. One year in review 2017: idiopathic inflammatory myopathies. Clin Exp Rheumatol 2017; 35 : $875-884$

[155] Cavagna L, Trallero-Araguas E, Meloni F et al. Influence of Antisynthetase Antibodies Specificities on Antisynthetase Syndrome Clinical Spectrum Time Course. J Clin Med 2019; 8. doi:10.3390/jcm8112013 